\title{
Business Analytics in Industry 4.0: A Systematic Review
}

\author{
António João Silva*1 $\mid$ Paulo Cortez ${ }^{2} \mid$ Carlos Pereira $^{3} \mid$ André Pilastri $^{4}$
}

\footnotetext{
${ }^{1}$ ALGORITMI Research

Center/Information Systems

Department, Universidade do Minho, Guimarães, Portugal, Email: id7322@alunos.uminho.pt

${ }^{2}$ ALGORITMI Research

Center/Information Systems

Department, Universidade do Minho,

Guimarães, Portugal, Email:

pcortez@dsi.uminho.pt

${ }^{3}$ Efacec, São Mamede de Infesta,

Portugal, Email: dee12014@fe.up.pt

${ }^{4}$ Centro de Computação Gráfica,

Guimarães, Portugal, Email:

andre.pilastri@ccg.pt
}

\begin{abstract}
Summary
Recently, the term "Industry 4.0" has emerged to characterize several Information Technology and Communication (ICT) adoptions in production processes (e.g., Internet-of-Things, implementation of digital production support information technologies). Business Analytics is often used within the Industry 4.0, thus incorporating its data intelligence (e.g., statistical analysis, predictive modeling, optimization) expert system component. In this paper, we perform a Systematic Literature Review (SLR) on this Business Analytics usage, covering a selection of 169 papers obtained from six major scientific publication sources from 2010 to March 2020. The selected papers were first classified in three major types, namely, Practical Application, Reviews and Framework Proposal. Then, we analyzed with more detail the practical application studies which were further divided into three main categories of the Gartner analytical maturity model, Descriptive Analytics, Predictive Analytics and Prescriptive Analytics. In particular, we characterized the distinct analytics studies in terms of the industry application and data context used, impact (in terms of their Technology Readiness Level) and selected data modeling method. Our SLR analysis provides a mapping of how data-based Industry 4.0 expert systems are currently used, disclosing also research gaps and future research opportunities.
\end{abstract}

KEYWORDS:

Artificial Intelligence, Industry 4.0, Machine Learning, Optimization, Predictive and Prescriptive Analytics

\section{1 | INTRODUCTION}

In the recent years, several industry sectors are being changed through the adoption of Information and Communication Technologies (ICT). More digital and connected sensors are being added to production systems, generating big data that can be processed using analytical systems, allowing to produce new insights and knowledge about the productive processes. Born in Germany in 2011 [BMBF[2011, the term "Industry 4.0" is widely used to identify this fourth industrial revolution. Indeed, the German Federal Ministry of Education and Research defines the Industry 4.0 concept as "the flexibility that exists in value-creating networks is increased by the application of cyber physical production systems. This enables machines and plants to adapt their behavior to changing orders and operating conditions through self-optimization and reconfiguration.... The main focus is on the ability of the systems to perceive information, to derive findings from it and to change their behavior accordingly, and to store knowledge gained from experience. Intelligent production systems and processes as well as suitable engineering methods and tools will be a key factor to successfully implement distributed and interconnected production facilities in future Smart Factories" [Shrouf, Ordieres, \& Miragliotta|2014].

Business Analytics is a major ICT tool for the Industry 4.0. It focuses in the analysis of historical raw data in order to achieve useful and focused insights and a better understanding of the business performance areas Krishnamoorthi \& Mathew 2018. Business Analytics is an expert systems subarea that results from the combination of Business Intelligence techniques with Optimization, Forecasting, Predictive Modeling and 
Statistical Analysis Arnott \& Pervan 2014]. Business Analytics systems are being increasingly applied in the Industry sector, thus behaving as the data intelligence component of the Industry 4.0. Indeed, Business Analytics can bring new advantages to the organizations such as product and process digitization, the creation of new products, services and solutions, the offering of Big Data Analytics as a service, the breadth of product customization and the mass production of custom products. There are also other potential advantages for industries, such as obtaining larger profit margins and increasing the market share of key business products by gaining valuable insights from customers using Data Analytics Geissbauer, Vedso, \& Schrauf 2016. Industries can gain efficiencies and lower costs by using real-time production line controls via Big Data Analytics. In addition, the Industry 4.0 offers production concepts that are modular, flexible and customer-tailored. Real-time visualization of the production process and variance of the product, as well as the use of data analytics for optimization and augmented reality, have emerged with the context of Industry 4.0. Predictive maintenance is another advantage that arises in this context because it uses forecasting algorithms to optimize the maintenance and repair processes. An increased vertical integration can be obtained by using sensors through the manufacturing execution system, allowing a real-time production planning with the objective of obtaining greater efficiency in terms of machine occupation times. Horizontal integration is another efficiency gain that allows track-and-trace products for better inventory management and improved operating speeds. Other efficiency gains include the digitization and automation of processes for a more efficient use of human resources Geissbauer et al.2016.

Given the emergence of this topic, this paper performs a Systematic Literature Review (SLR) on the usage of Business Analytics within the Industry 4.0 concept, which a particular focus on practical applications and three main types of analytics (Descriptive, Predictive and Prescriptive). The specific Research Question (RQ) addressed by this SLR is: How and in what areas of the industry are Business Analytics techniques being used in an Industry 4.0 context? To answer the RQ, a total of 168 papers, from 2010 to March 2020, were selected for the review. Then, the practical studies were further analyzed, allowing to identify the specific industrial context where analytics were used (e.g., business goal, data used), the selected modeling method (e.g., analysis of variance, artificial neural networks) and the obtained impact. Thus, the performed SLR characterization summarizes how Industry 4.0 expert systems are being used, also disclosing current research gaps that can be addressed in future research works.

This article is structured as follows. Section 1 presents an introduction and conceptualization of the two main topics analysed in this SLR: Industry 4.0 and Business Analytics. Section 2 describes similar research literature surveys, contrasting them with this SLR. The SLR method is presented in Section 3 Then, the executed SLR is detailed in Section 4 and discussed in Section 5 Finally, Section 6 presents the main conclusions and research implications of this literature review.

\section{1 | Business Analytics}

The Business Analytics topic assumes the Big Data age in an extensive manner. It also includes useful data processing decision support methods, namely Optimization, Forecasting, Predictive Modeling, and Statistical Analysis. The goal is to extract useful, often actionable knowledge from historical data based on advanced Artificial Intelligence (Al) analytics Arnott \& Pervan 2014. G. Cao, Duan, \& Li 2015 H. Chen, Ling Li, \& Chen 2020 Koch 2015 Lu 2019]. In 2013, the the famous Gartner Group defined four main types of analytics: Descriptive, Diagnostic, Predictive and Prescriptive. The Descriptive analysis attempts to answer the question "what happened?". Business Intelligence (BI) and Big Data systems (e.g., Data Warehousing) can be used to access the historical data and provide summarization reports, visualizations and dashboards (e.g., pie charts, bar charts, table or generated views). Next, the Diagnostic analysis aims to understand "why did it happen?", using mostly exploratory data analysis techniques via a interaction with the data analyst which is looking for insights. For example, by visualizing drill down/up operations of an online analytical processing tool of a Data Warehousing. Then, the Predictive analysis aims to answer the question "what will happen?". This can be achieved by using Statistical Analysis and Machine Learning (e.g., Classification, Regression, Time-Series Forecasting). Predictive Analytics are being used in diverse application domain areas, such as Marketing Chi-Hsien \& Nagasawa 2019] and Finance Swamy \& B. Sarojamma 2020. The last and most difficult analytic type is termed Prescriptive Analysis and it is related with the question "how can make it happen?". This type of analytics can be achieved by using diverse techniques, including Simulation, What-if scenarios, Machine Learning, Heuristics and Optimization. We note that Diagnostic analytics are often difficult to distinguish from Descriptive ones, since both are assumed to analyze historical data and are often performed simultaneously by the same analysts. Thus, in this paper, we adopt the same strategy used by Chong and Hui Shi 2015 and Khatri and Samuel 2019], which group all historical analyses (Descriptive or Diagnostic) into a single Descriptive analytics category.

\section{2 | Industry 4.0}

The Industry 4.0 is defined as the global transformation of the manufacturing industry through the introduction of digitalization and the Internet. The transformations applied imply enormous advances in the design and the manufacturing processes, operations and services of manufacturing products and systems. The term Industry 4.0 was coined in Germany in 2011 and it shares similarities with developments produced in many European countries and that have been labelled differently, as Smart Factories, Smart Industry, Advanced Manufacturing of Internet of Things (loT) BMBF 2011. Tjahjono, Esplugues, Ares, \& Pelaez 2017. The term Industry 4.0 was born in Germany because the German engineers realized 
that manufacturing had been developed into a new paradigm shift, where products tend to control their own manufacturing process Lasi, Fettke, Kemper, Feld, \& Hoffmann 2014]. The Industry 4.0 is considered the fourth industrial revolution, which contains a extreme potential impact in the future Kagermann, Helbig, Hellinger, \& Wahlster 2013. Smart Factories use new technologies, such as advanced robotics and Al, cloud computing, IoT, Data Analytics, Software-as-a-Service and platforms that use algorithms to direct motor vehicles, delivery and ride services, and the embedding of all these elements, and many more, in an interoperable global value chain, shared by many companies from different countries Geissbauer et al. 2016.

Until recently, the term Industry 4.0 has not yet been conclusively defined, neither are its features. Nevertheless, there are four main features that typically categorizes the term Tjahjono et al.2017]: vertical networking of smart production systems; horizontal integration via a new generation of global value chain networks; through-life engineering support across the entire value chain; and acceleration through exponential technologies. This perspective of the analysis is believed to be relevant since there is no complete or concise knowledge of how to implement Industry 4.0 correctly or predict future problems to be prevented in advance. The use of loT and Cyber-Physical Systems (CPS) on Industry 4.0 made possible the connection between materials, sensors, machines, products, supply chain, and customers, which means these necessary objects are going to exchange information and control actions with each other independently and autonomously. The technologies that support the Industry 4.0 concept are the loT, CPS, Cloud Computing and Big Data Analytics (Lasinkas 2017. These concepts are described in the next subsections.

\subsection{1 | IoT}

The concept of loT describes an inter-networking world where various objects inside of that world are embedded with sensors, and other digital devices, so they can be networked in order to be possible to collect and exchange data from them Xia, Yang, Wang, \& Vinel 2012. loT-enabled manufacturing features real-time data collection and sharing among various manufacturing resources such as machines, workers, materials, and jobs. Usually, the loT can provide advanced connectivity of various objects, systems and services, and enable data sharing. loT is particularly useful for industries Zhong, Xu, Klotz, \& Newman 2017]. In the future, it is expected to occur a convergence of loT-related technologies, such as ubiquitous wireless standards, Data Analytics and Machine Learning (L. D. Xu, He, \& Li 2014 Zhong et al. 2017]. loT is being applied in other sectors besides Industry, such as in the Healthcare area where loT is being combined with Machine Learning techniques to predict lung cancer in patients Pradhan \& Chawla 2020.

The Radio-Frequency Identification (RFID) is an example of a technology that is used in loT. The manufacturing industry will be affected by this change because RFID is used for identifying various objects in warehouses, distribution centers, production shop floors, logistic companies and disposal/recycle stages Y.-M. Wang, Wang, \& Yang 2010. The identifiers have smart sensing abilities, and they can connect and interact with other objects, which may create a huge amount of data from their movements and behaviors. These objects are given specific applications or logics, so that they can be followed after being equipped with the RFID readers and tags Guo, Ngai, Yang, \& Liang 2015. RFID can also capture data related to the daily operations so that production management is achieved on a real-time basis (Zhong et al. 2017).

\subsubsection{Cyber-Physical Systems}

A CPS involves a various number of methodologies such as cybernetics theory, mechanical engineering and mechatronics, design and process science, manufacturing systems, and computer science. The ability to have highly coordinated and combined relationships between physical objects and their computational elements or services is one of the key elements of a CPS [Tan, Goddard, \& Pérez 2008. Unlike a traditional embedded system, the CPS contains networked interactions that are developed and designed with inputs and outputs, along with their cyberwined services, such as computational capacities and control algorithms. A large number of sensors have crucial roles in a CPS. For example, multiple sensory devices can be used in a large number of purposes such touch screens, light sensors, and force sensors [Zhong et al. 2017.

One example of a real-world project with CPS is the Festo Motion Terminal, which aims to create a standardized platform that makes full use of an intelligent fusion of mechanics, electronics, embedded sensors and control Zhong et al.[2017. However, the typical CPS applications have been reported for using sensor-based communication-enabled autonomous systems, and a various number of wireless sensor networks can supervise aspects such as environmental so that information can be centrally controlled and managed for decision-making [Ali et al. 2015].

\subsubsection{Cloud Computing}

The general term that describes computational services through visual and scalable resources over the Internet is cloud computing Armbrust et al.2010 X. Xu 2012. Cloud computing is interesting for business owners because the advantage of scalability allows organizations to start small and invest in more resources if the service demand goes up Q. Zhang, Cheng, \& Boutaba 2010.

An ideal cloud service must have these five characteristics Mell \& Grance 2011: on-demand self-service, broad network access, resource pooling, rapid elasticity, and measured service. The ideal cloud service model is composed of four deployment models (public, private, community, and hybrid) and three delivery models (Software-as-a-Service, Platform-as-a-Service, and Infrastructure-as-a-Service). Cloud computing services 
are being implemented by all kind of organizations to increase their capacity with a minimum budget investment, as cloud computing does not require investments in new software, incorporate new infrastructures or train new personal Saxena \& Pushkar 2016.

Despite the benefits of cloud computing, this technology also has challenges, in particular related with privacy and security concerns. Other challenges, such as data management and resource allocation, scalability and communication between clouds, reduce the reliability and efficiency of cloud-based systems [Zhong et al. 2017]. Because of its relative innovation and increasing development in recent years, a great body of research has been conducted on cloud computing $[$ H. Yang \& Tate 2009].

\subsection{4 | Big Data Analytics}

The Big Data trend was mostly motivated by the use of Internet and loT technologies, which generate vast amounts of data in various industries Manyika et al.2011. Big Data stems from various channels such as sensors, devices, networks, transitional applications and social media feeds Rich 2012. The Big Data environment has gradually taken shape in the manufacturing sector. Besides the advance of the loT and the collection of data, there are questions to be resolved, such as how to collect and store the Big Data obtained from real-time sensors which can be processed properly in order to provide the right information for the right question at the right time (J. Lee, Lapira, Bagheri, \& Kao 2013. Y. Chen et al. 2016. defined Big Data Analytics as the fusion of Big Data and loT technologies that created opportunities for the development of services for smart environments like smart cities. Nowadays, there are a set of Big Data technologies available to process the large data obtained from the loT devices which have emerged as a need to process the data collected from different sources in the smart environment.

The Big Data datasets are much larger than the normal datasets, thus they can be too complex for conventional data analytics software Barton \& Court 2012. As such, it is essential for organizations and manufacturers with vast operational shop-floor data to have advanced analytics techniques for uncovering hidden patterns and unknown correlations between the data, or other things such as market trends, customer preferences and other information useful for the business [Zhong et al. 2017]. The particular concept of Big Data Warehouse (BDW) emerged due to the studies made about the applications of BDW in Big Data Krishnan 2013 Mohanty, Jagadeesh, \& Srivatsa 2013. Actually, the state-of-the-art refers that the design of BDW should focus on the physical layer and logical layer using two strategies. The first strategy, "lift and shift", is the use of Big Data technologies to solve specific cases and augment the capabilities of traditional and relational Data Warehouses. However, the use of a case driven approach instead of a data modeling approach can lead to possible uncoordinated data silos Clegg 2015 Russom 2014. The second strategy, "rip and replace", is where occurs a replace of the Data Warehouse in favor of Big Data Technologies Russom 2014 2016. In this field, a number of literature reviews were performed; however, they did not focused on the application of Big Data Analytics in Industry 4.0. Duan and Ye Xiong 2015 performed a literature review about the use of Big Data Analytics and Business Analytics, and they concluded that the Big Data concept implies the investment in equipment to capture and store data combined with a Business Analytics approach linked to each business strategy and organizational process, and being aware with the evolving of the state-of-the-art techniques in Big Data. Chong and Hui Shi] 2015) studied the use of Big Data Analytics and concluded that these techniques can help the decision-making process, increase the business model understanding, and reveal hidden information to attain competitive advantage.

\section{2 | RELATED WORK}

There are several reviews about the implementation of analytical techniques in the Industry 4.0 context. O'Donovan, Leahy, Bruton, and O'Sullivan 2015 made a mapping study about the use of Big Data in the manufacturing sector. The research method was performed manually. Chiang, Lu, and Castillo 2017) reviewed the recent advances of Big Data in data-driven approaches in five industries inside the manufacturing sector. Similarly to O'Donovan et al. 2015, the study only focused on the use of Descriptive and Diagnostic Analytics techniques. Nikolic, Ignjatic, Suzic, Stevanov, and Rikalovic 2017. made a review about Predictive Analytics in the Industry 4.0 context. The authors searched and reviewed different types of Predictive Maintenance systems. They provided an overview of the various challenges, existing solutions, and benefits of Predictive Manufacturing systems in Industry 4.0. Qi and Tao 2018 reviewed the state of Big Data and digital twins in the manufacturing sector. This review also included the applications in product design, production planning, manufacturing, and predictive maintenance. On this basis, the similarities and differences between Big Data and digital twins were compared from the general and data perspectives. Uhlmann, Hohwieler, and Geisert 2017 made a literature review about the historical development of intelligent production systems in the context of adding value to business models. They focused on techniques such as the use of barcodes, RFID, and wireless sensor nodes to make condition monitoring and Predictive Maintenance in the availability oriented business model. They also studied, based on practical examples, the organizational prerequisites for an implementation of these techniques in the industry. X. Xu and Hua 2017. summarized and analyzed the current research status for industrial Big Data Analysis in smart factories (both domestic and abroad). Also, they proposed research strategies for Industrial Big Data Analysis, including acquisition schemes, ontology modeling, predictive diagnostic methods based on Deep Neural Networks (DNN) and three-dimensional self-organized reconfiguration mechanism. In the area of Augmented Reality solutions, J. Yang, Chen, Huang, and Li 2017) presented a comprehensive survey of Al in 3D painting 
TABLE 1 Literature surveys about the topic of Business Analytics in Industry 4.0

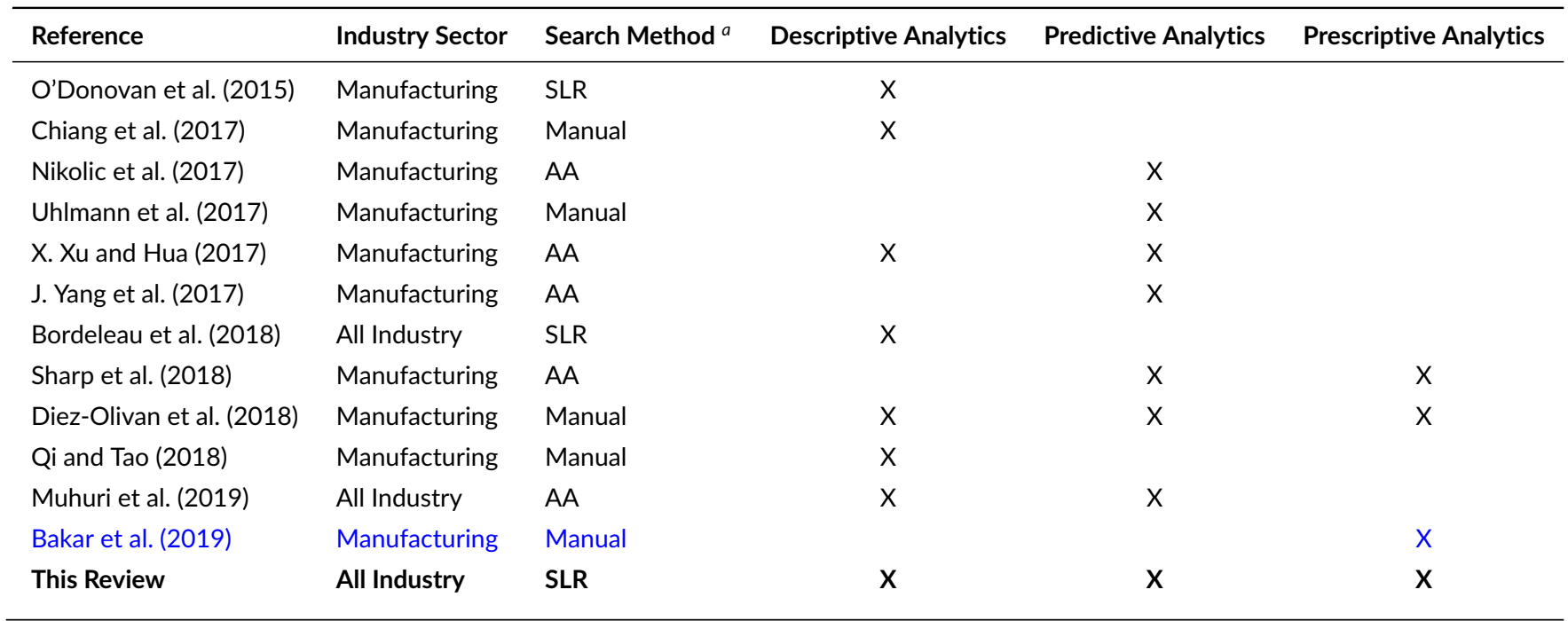

${ }^{a}$ Automatic Analysis (AA), Systematic Literature Review (SLR)

to detect defective products in the Industry 4.0 context. The survey only analyzed Predictive Analytics techniques. Bordeleau, Mosconi, and SantaEulalia 2018 also performed a literature review of Business Intelligence in the context of Industry 4.0. The goal was to understand how Business Intelligence and data analysis generate value creation in manufacturing companies. This review only studied Descriptive Analytics. Sharp, Ak, and Hedberg 2018, presented another literature review about the use and development of Machine Learning in smart manufacturing. We note that this review studied practical cases that used Machine Learning in contexts different to the Industry 4.0 context. They reviewed the articles published between 2007 until 2017, while the Industry 4.0 concept was introduced in the 2010s. Moreover, the authors only analyzed the Diagnostic and Predictive Analytics. More recently, Diez-Olivan, Del Ser, Galar, and Sierra 2018, presented a survey of the recent developments in data fusion and Machine Learning for industrial prognosis during the Industry 4.0 context. In the same year, Muhuri, Shukla, and Abraham 2019 performed a literature review about the growth of the Industry 4.0 in the last years. Bakar, Ramli, Sin, and Masran 2019] presented a survey regarding the use of Metaheuristics techniques and Robotic Assembly Line Balancing in the Manufacturing industry. This SLR review is more focused on the whole Industry 4.0 concept, and thus it does not detail much the Business Analytics methods.

A summary of the related work is presented in Table 1 None of the reviews analyzed addressed all main Gartner's Analytical levels. In contrast, this SLR contains a stronger focus on the Descriptive, Predictive and Prescriptive analytics, when applied to the context of the Industry 4.0. Moreover, we particularly detail the practical applications, allowing to characterize the main business goals, data usage, modeling methods and obtained impacts. It should also be noted that most surveys consider only the Manufacturing sector, which is where the Industry 4.0 concept is producing a higher impact. Indeed, while this SLR considers all industry sectors, the selected practical research works in this SLR are highly related with the Manufacturing sector (as shown in Section 4.1.2.

\section{3 | LITERATURE REVIEW METHOD}

\subsection{Paper Collection}

We performed a manual SLR review, similar to what was proposed by Kitchenham et al. 2009]. For this literature review, we used several scientific search engines, in order to search for the relevant documents: Google Scholar https://scholar.google.com/, Google Books https:// books.google.com/, ScienceDirect https://www.sciencedirect.com/, SpringerLink https://link.springer.com/, Scopus https://www .scopus.com/home.uri and IEEE Xplore https://ieeexplore.ieee.org/Xplore/home.jsp. The term "Industry 4.0" was coined in 2010. As shown in Figure 1 the Web interest in the term starts from 2010, although the popularity only increases substantially after 2014 . Thus, we have retrieved articles that were published since 2010 until March 2020 (when this SLR was executed). Using the listed search engines, we performed several queries, using the combinations of the following keywords: "Industry 4.0", "Decision Support Systems", "Business Analytics", "Predictive Analytics", "Machine Learning", "Data Mining", "Text Mining", "Process Mining", "Forecasting", and "Metaheuristic". Table 2 presents the literature search protocol used during this SLR. 
Industry 4.0 in Google Trends

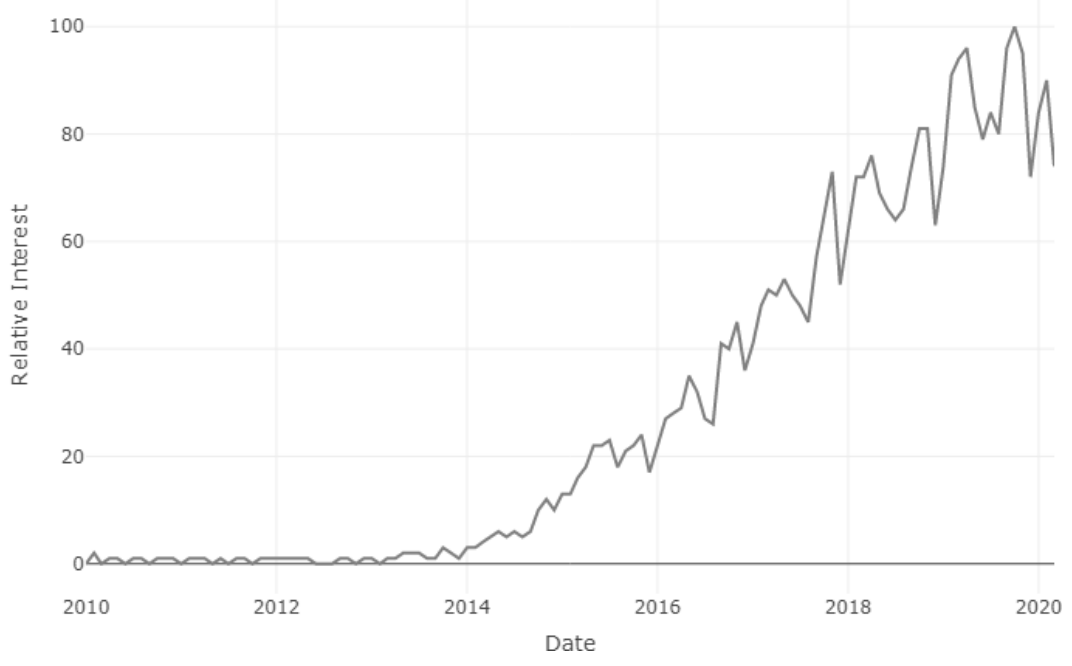

FIGURE 1 Evolution of the interest in the term "Industry 4.0" in Google Trends

TABLE 2 Summary of the literature search protocol

\begin{tabular}{ll}
\hline Subject & Business Analytics in Industry 4.0 \\
\hline Time period & January 2010 to March 2020 \\
\hline Search Engines & Scopus, ScienceDirect, SpringerLink, IEEE Xplore, Google Scholar, Google Books \\
\hline Search Criteria & English; Title, abstract and keywords OR All (except full text) \\
\hline Search Query & "Industry 4.0 + Decision Support Systems", "Industry 4.0 + Business Analytics", "Industry 4.0 + \\
& Predictive Analytics", "Industry 4.0 + Machine Learning", "Industry 4.0 + Data Mining", "Industry \\
& 4.0 + Text Mining", "Industry 4.0 + Process Mining", "Industry 4.0 + Forecasting", "Industry 4.0 + \\
& Metaheuristic" \\
\hline
\end{tabular}

\subsubsection{Paper Selection}

Table 3 presents the distribution numbers of the collected scientific publications for the different search engines used. The paper search queries resulted in a total of 285 articles. All retrieved documents were manually inspected to check their relevance. First, the title and abstract was read. When the abstract was not conclusive, a more in-depth reading of the article was performed, in order to verify if the document fits the SLR goal. The manual inspection filtered 116 papers that were considered irrelevant for the survey, thus resulting in a total of 169 articles that were selected.

\section{4 | LITERATURE REVIEW ANALYSIS}

\section{1 | Quantitative Analysis}

As stated earlier, 169 papers were selected for this literature review. To make a general overview about the papers selected, a quantitative analysis was performed, in which the papers are characterized according to the year of publication and the paper type.

\subsubsection{Paper type}

The papers collected were manually inspected and divided into the three different categories proposed in Öchsner 2013:

- Practical Application - These papers describe and discuss real implementation results of a framework, methodology, method or information technology in one or more application domain areas; 
TABLE 3 Distribution of papers obtained by each database

\begin{tabular}{lc}
\hline Database & Quantity \\
\hline Scopus & 202 \\
ScienceDirect & 75 \\
SpringerLink & 35 \\
IEEE Xplore & 60 \\
Google Scholar & 35 \\
Google Books & 5 \\
\hline Total with duplicates & 390 \\
\hline Total without duplicates & 285 \\
\hline
\end{tabular}

- Reviews - Articles of literature review (such as this paper), with the main objective of performing a survey of the state-of-the-art on a certain scientific research topic area, possibly identifying research gaps; and

- Framework Proposal - The aim is to document the proposal of a new framework developed by the authors. However, these articles do not have a specific application target, thus the authors do not validate the framework in a real-world environment.

Table 4 shows the respective distribution of the selected 169 papers in terms of the three main paper categories. The majority of the selected

TABLE 4 Distribution of the three main paper types

\begin{tabular}{lc}
\hline Paper Type & Quantity \\
\hline Practical Application & 139 \\
Reviews & 12 \\
Framework Proposal & 18 \\
\hline Total & 169 \\
\hline
\end{tabular}

papers are Practical Application ones (139 papers). There are 11 papers that were categorized as Reviews and 18 publications categorized as Framework Proposal. Given that this survey is more focused on practical usage of Business Analytics, we will only further detail and analyze the 139 Practical Application studies. The quantitative analysis includes the industry sector, the Gartner Analytic type and year, and finally the paper keyword frequencies.

\subsubsection{Industry sectors of the Practical Applications}

To describe the Industry sections we adopted the Standard Industrial Classification Bureau 2017, which includes five main categories listed in Table 5 The Manufacturing sector is by a large margin the sector with most Industry 4.0 practical applications of Business Analytics, with 130 papers. This happens because the manufacturing sector is a vast sector that includes a relevant number of production processes, widely used by several industries. The manufacturing sector has also high Business Analytics needs. For instance, the shop floor usually has different kinds of machines, which should work efficiently and produce quality products. Thus, Predictive Maintenance and automatic quality inspection/prediction methods, based on data-driven models, can be used to enhance the manufacturing process.

The other industry sectors have much less practical application works. Within the Transportation and Warehousing and Utilities sector, the surveyed papers relate with three practical applications. In the Eolic Energy area, Canizo, Onieva, Conde, Charramendieta, and Trujillo 2017. presented a data-driven solution deployed in a cloud that used Random Forest (RF) for predicting failures on wind turbines. In the transformation energy field, Bagheri, Zollanvari, and Nezhivenko 2018 analyzed the analytical approach to the transformer vibration modeling, using Machine Learning techniques such as Linear Regression (LR), Model Trees, Support Vector Regression with Gaussian Kernel and Multilayer Perceptron, and also signal techniques to develop prognosis models of transformer operating condition based on vibration signals. Masoudinejad et al. 2018. proposed a set of Support Vector Machine (SVM) algorithms, addressing indoor localization within a warehouse. The Construction sector has two 
TABLE 5 Distribution of the Practical Applications per industry sector

\begin{tabular}{lc}
\hline Industry Sector & Quantity \\
\hline Manufacturing & 130 \\
Transportation and Warehousing and Utilities & 3 \\
Construction & 2 \\
Educational Services, and Health Care and Social Assistance & 1 \\
Agriculture, Forestry, Fishing, and Hunting, and Mining & 2 \\
Finance and Insurance, and Real Estate, and Rental and Leasing & 1 \\
\hline Total & 139 \\
\hline
\end{tabular}

TABLE 6 Distribution of the Practical Applications for the three Analytics types and year of publication

\begin{tabular}{ccccc}
\hline Year & $\begin{array}{c}\text { Descriptive } \\
\text { Analytics }\end{array}$ & $\begin{array}{c}\text { Predictive } \\
\text { Analytics }\end{array}$ & $\begin{array}{c}\text { Prescriptive } \\
\text { Analytics }\end{array}$ & Total \\
\hline 2015 & 2 & 0 & 0 & 2 \\
2016 & 2 & 8 & 2 & 12 \\
2017 & 8 & 17 & 2 & 27 \\
2018 & 9 & 21 & 5 & 35 \\
2019 & 2 & 25 & 10 & 37 \\
2020 & 0 & 9 & 8 & 17 \\
\hline Total & 23 & 80 & 27 & 130 \\
\hline
\end{tabular}

practical applications. J. Lee, Kao, and Yang 2014 made a review about the trend of the manufacturing service transformation in Big Data and proposed a framework for sustainable innovative service. The data used to make the case study came from sensors installed in a bulldozer. They used a Bayesian Belief Network to classify if the engine had some problem or malfunction and used a Fuzzy-Logic based algorithm to predict the remaining useful life of the engine. R. Costa, Figueiras, Jardim-Gonçalves, Ramos-Filho, and Lima 2017. proposed a system with the aim to create knowledge representations from unstructured data sources used in a construction environment, based on enriched semantic vectors. Regarding the Educational Services, and Health Care and Social Assistance sector, Bordel and Alcarria 2017. presented a solution to automatically assess the human motivation in Industry 4.0 scenarios with the use of an ambient intelligence infrastructure. Turning to the Agriculture, Forestry, Fishing, and Hunting, and Mining sector, Teschemacher and Reinhart 2017) used Ant-Colony Optimization (ACO) algorithms to enable dynamic milk-run logistics. Also, Dutta, Mueller, and Liang 2018, implemented a Machine Learning based interactive architecture for industrial scale prediction for dynamic distribution of water resources across the continent and, at the same time, keeping four corners of Industry 4.0 in place. The algorithms tested were LR, Bayesian Ridge Regression, Logistic Regression, Linear Discriminant Analysis, Adaptive Neuro-Fuzzy Inference System, Multi-Layer Perceptron (MLP), and Radial Basis Function Network. Finally, within the Finance and Insurance, and Real Estate, and Rental and Leasing sector, Ma and Li 2018] used a Grey Model (GM) to predict eight indexes of the tertiary industry.

\subsection{Analytics Type}

Table 6 shows the distribution of the selected Practical Application papers in terms of publication year and analytics type. The most common type is the Predictive Analytics level, with 80 applications, followed by the Prescriptive Analytics, with 27 applications, while the Descriptive Analytics were only addressed in 23 applications. The smaller number associated with the Prescriptive and Descriptive Analytics denote an important research gap. The lack of further Prescriptive studies is probably due to two main reasons. Firstly, the Industry 4.0 concept implementation is very recent (just a few years). Most of its initial implementation effort is devoted to setting the right infrastructure to generate and collect data, and Business Analytics can only be applied after collecting enough historical data. Secondly, Prescriptive Analytics are more complex than other types of data analyses Koch 2015. As more mature Industry 4.0 applications are implemented, we expect this gap to be reduced. It is also interesting to note that there are more Predictive Application studies than Descriptive ones. This behaviour might be explained by the current Machine Learning hype. Also, building a stable and valuable Data Warehousing system, which results in better Descriptive analysis, requires several Extract, Transform, Load (ETL) 


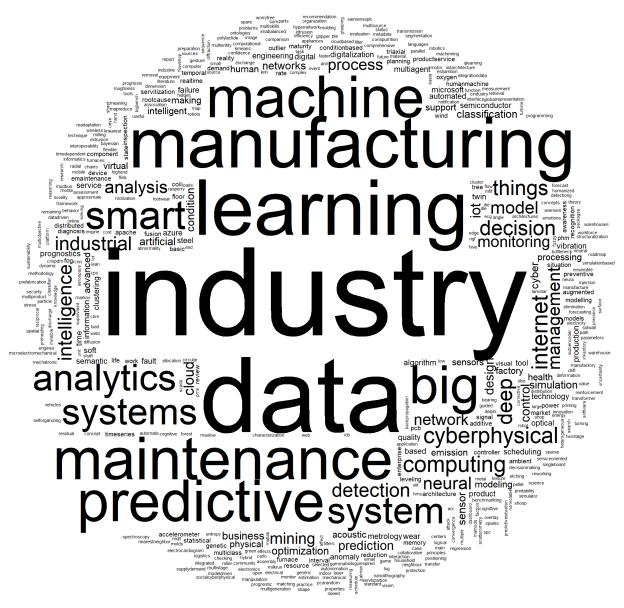

\begin{tabular}{|c|c|c|}
\hline & Term & Frequency \\
\hline 1 & industry & 74 \\
\hline 2 & data & 63 \\
\hline 3 & learning & 46 \\
\hline 4 & manufacturing & 42 \\
\hline 5 & maintenance & 35 \\
\hline 6 & machine & 34 \\
\hline 7 & predictive & 34 \\
\hline 8 & big & 31 \\
\hline 9 & smart & 23 \\
\hline 10 & analytics & 21 \\
\hline
\end{tabular}

FIGURE 2 Word cloud of the keywords (left) and top 10 term frequency values (right)

processes that are often costly, requiring manual effort and time, but that do not tend to translate into novel methodologies or interesting application usages that justify a research publication. Overall, the yearly numbers from Table 6 show a substantial growth in the number of publications starting from 2017: 25 papers in 2017; 34 works in 2018; and 31 research publications in 2019 (the 8 papers from the year of 2020 report only until the month of March).

\subsubsection{Keywords frequencies}

The last quantitative analysis is obtained by applying a word cloud technique to the 112 application paper keywords. We have selected keywords because these help to index and classify papers, facilitating research queries. The word cloud analysis was performed using R tool with the package wordcloud. The word cloud is presented in Figure 2 which also details the top term frequency numeric values. The most frequent term is "Industry", followed by "data", "learning" and "manufacturing". Other terms such as "maintenance", "machine" and "predictive" are also popular, which aligns with Table 6 since most practical applications use Predictive Analytics.

\section{3 | Qualitative Analysis}

The qualitative analysis was executed by a manual inspection of the selected practical papers. The description of practical cases are divided by the analytics type (Descriptive, Predictive and Prescriptive), using a chronological order. Each practical application is briefly described, including the:

- Function - Industry 4.0 function area, which is categorized by the four main functions of the Industry 4.0 architecture presented by Qin, Liu, and Grosvenor 2016: Hardware Connection (HC), focuses on hardware development (e.g., sensor network); Information Discovery (ID), where the raw data is transformed into useful knowledge; Predictive Maintenance (PdM), aiming to anticipate maintenance issues; and Intelligent Production (IP), automating or adapting the production process.

- Data - type of industry data used (e.g., generated by a production machine, captured image).

- Sector - addressed industry sector (e.g., aerospacial, automotive).

- Goal - brief description of the application goal.

- Impact - measured using the Technology Readiness Level (TRL) scale, from 1 to 9 (Table 7) [ESRTC 2009].

- Modeling - Business Analytics method used to analyse the data.

\subsection{1 | Descriptive Analytics}

Table 8 presents an overview of the practical applications that used Descriptive Analytics techniques. As shown in the table, there is a diversity of Descriptive applications and adopted types of historical analyses. For instance, some studies perform a simple statistical analysis Birglen \& 
TABLE 7 Description of the Technology Readiness Levels (TRL)

\begin{tabular}{lll}
\hline Phase & Level & Definition \\
\hline \multirow{3}{*}{ Research } & TRL 1 & Basic research \\
& TRL 2 & Technology formulation \\
& TRL 3 & Concept validation \\
\hline \multirow{3}{*}{ Development } & TRL 4 & Prototype in laboratory environment \\
& TRL 5 & Prototype in relevant environment \\
& TRL 6 & Prototype system tested in relevant environment \\
\multirow{2}{*}{ Deployment } & TRL 7 & Demonstration system in operational pre-commercial environment \\
& TRL 8 & First commercial system, ready for operational environment \\
& TRL 9 & Full commercial system with general availability \\
\hline
\end{tabular}

Schlicht 2018 Lenz, Wuest, \& Westkämper|2018 Mozgova, Yanchevskyi, Gerasymenko, \& Lachmayer|2018 Niño, Blanco, \& Illarramendi|2015 Sanz, Matey, Blesa, \& Puig 2017 Stürmlinger, Haar, Pandtle, \& Niemeyer|2018 Tang et al.2016 Ventura et al.|2019], while others use more sophisticated outlier detection Y.-M. Lee, Lin, Li, Xiangqian, \& Li 2016 Trunzer et al.2017] and clustering methods Y. Wang et al.|2017. Some studies use data warehousing databases and dashboards Kirchen, Schütz, Folmer, \& Vogel-Heuser 2017 Neuböck \& Schrefl 2015 Vathoopan, Johny, Zoitl, \& Knoll2018 Zheng \& Wu|2017, and other studies used Neural Networks Kaupp, Beez, Hülsmann, \& Humm2019 C.-J. Kuo, Ting, Chen, Yang, \& Chen|2017 Qin, Liu, \& Grosvenor 2017 Subakti \& Jiang|2018 Tieng et al.|2018.

TABLE 8 Overview of the Practical Articles that used Descriptive Analytics Techniques

\begin{tabular}{|c|c|c|c|c|c|c|}
\hline Reference & Func ${ }^{1}$ & Data $^{2}$ & Sectol $^{3}$ & Goal & Impact & Modeling ${ }^{4}$ \\
\hline $\begin{array}{l}\text { Neuböck and } \\
\text { Schrefl 2015 }\end{array}$ & & $\operatorname{Pr}$ & ND & $\begin{array}{l}\text { New analysis graphs are proposed for building production insights (e.g., } \\
\text { show urgent missing materials). }\end{array}$ & & DW, AG \\
\hline Niño et al. & & MF & CE & Big Data Analytics for pursuing a servitization strategy. & 2 & DA \\
\hline $\begin{array}{l}\text { Y.-M. Lee et al. } \\
2016 \text {. }\end{array}$ & & $\mathrm{S}$ & A & $\begin{array}{l}\text { Real-time analysis to explore the reasons for abnormality of load rate data } \\
\text { of main shaft machine. }\end{array}$ & & $\begin{array}{l}\text { BPANN, } \\
\text { TSC }\end{array}$ \\
\hline Tang et al. & $\mathrm{HC}$ & MF & ND & Intelligent architecture for the smart shop floor. & 5 & NEIMS \\
\hline \begin{tabular}{|l|} 
Durakbasa, \\
Bauer, and \\
Poszvek 2017) \\
\end{tabular} & ID & $\mathrm{S}$ & ND & Improve the quality of the manufacturing process. & 2 & $\mathrm{FL}$ \\
\hline Kirchen et al. & & $\mathrm{S}$ & $\mathrm{Cl}$ & Explore signal data quality. & 4 & DA \\
\hline $\begin{array}{l}\text { C.-J. Kuo et al. } \\
2017 .\end{array}$ & IP & $\mathrm{S}$ & SM & $\begin{array}{l}\text { Explore inexpensive add-on triaxial sensors for the monitoring of machin- } 5 \\
\text { ery. }\end{array}$ & & NN \\
\hline Qin et al. 2017. & ID & $M C$ & AM & $\begin{array}{l}\text { Facilitate a better understanding of the energy consumption of digital } \\
\text { production processes. }\end{array}$ & & $\begin{array}{ll}\text { LinR, } & \text { DT, } \\
\text { BPNN }\end{array}$ \\
\hline
\end{tabular}

\footnotetext{
${ }^{1}$ Hardware Connection (HC), Information Discovery (ID), Intelligent Production (IP), Predictive Maintenance (PdM)

${ }^{2}$ Car Specification (CS), Grippers (G), Historical (H), Machine (MC), Manufacturing (MF), Production (Pr), Sensor (S), Sparse Data (SD), Temporal Logs (TL)

${ }^{3}$ Additive Manufacturing (AM), Aerospace (As), Automotive (A), Capital Equipment (CE), Chemical Industry (CI), Glass Industry (GI), Not Disclosed (ND), Semiconductor (SC), Spring Manufacturing (SM)

${ }^{4}$ Analysis Graph (AG), Artificial Neural Networks (ANN), Augmented Reality (AR), Back-Propagation Artificial Neural Networks (BPANN), BackPropagation Neural Networks (BPNN), Browns Double Exponential Smoothing (BDES), Classification Trees (CT), Clustering (Cl), Cross-Departmental Data Analytics (CDDA), Data Analysis (DA), Data Warehouse (DW), Decision Trees (DT), Deep Learning (DL), Descriptor Silhouette (DS), Digital Twin (DigT), Failure Mode Metrics (FMM), Fuzzy Logic (FL), Genetic Algorithm (GA), Interpolation Fitting (IF), K-Mean Clustering (KMC), Linear Regression (LinR), Monkey Algorithm (MA), Neural Networks (NN), NeuroEndocrine-Inspired Manufacturing System (NEIMS), Partial Least Square (PLS), Residual Prediction Calculator (RPC), Self Organizing Map (SOM), Simulation (Sim), Standard Silhouette (SS), Two-Stage Clustering (TSC)
} 


\begin{tabular}{|c|c|c|c|c|c|}
\hline $\begin{array}{l}\text { Sanz et al. ID } \\
\text { 2017. }\end{array}$ & $\mathrm{S}$ & A & $\begin{array}{l}\text { Advanced monitoring of an industrial process that integrates several data } 3 \\
\text { sources. }\end{array}$ & & BDES \\
\hline Trunzer et al. ID & $\mathrm{S}$ & ND & Classify failures in control valves. & 4 & FMM, GA \\
\hline $\begin{array}{l}\text { Y. Wang et al. ID } \\
\text { 2017. }\end{array}$ & SD & ND & Methodology to enrich sparse data by fast and frugal reduced models. & 3 & $\mathrm{Cl}, \mathrm{CT}$ \\
\hline $\begin{array}{l}\text { Zheng and } \mathrm{Wu} \text { ID } \\
2017\end{array}$ & $\operatorname{Pr}$ & SC & Smart spare parts inventory management system for semiconductors. & 5 & DA, Sim \\
\hline $\begin{array}{l}\text { Birglen and ID } \\
\text { Schlicht 2018 }\end{array}$ & G & A & $\begin{array}{l}\text { Review the characteristics of pneumatic, parallel, two-finger and industrial } 3 \\
\text { grippers. }\end{array}$ & & DA \\
\hline Lenz et al. ID & $\mathrm{S}$ & ND & Holistic approach for machine data analytics. & 2 & CDDA \\
\hline C. Lin and Yang $\mathrm{HC}$ & $\mathrm{S}$ & ND & $\begin{array}{l}\text { Intelligent Computing System to connect the different facilities in a logistic } \\
\text { center. }\end{array}$ & & MA, GA \\
\hline Mozgova et al. ID & S & A & $\begin{array}{l}\text { Monitor actual stress state of a structural component and estimate its } \\
\text { residual fatigue life. }\end{array}$ & & RPC \\
\hline $\begin{array}{l}\text { Ploennigs, ID, HC } \\
\begin{array}{|l}\text { Ba, and Barry } \\
2018 \\
\end{array}\end{array}$ & S & ND & Cognitive loT architecture with scalability and self-learning capabilities. & 5 & AR \\
\hline $\begin{array}{l}\text { Stürmlinger et } \mathrm{HC} \\
\text { al. } 2018 \text {. } \\
\end{array}$ & S & ND & Development of a new generation of a manufacturing system. & 5 & DA \\
\hline $\begin{array}{l}\text { Subakti and ID } \\
\text { Jiang 2018. }\end{array}$ & MC & ND & $\begin{array}{l}\text { Augmented reality system to visualize and interact with machines in smart } \\
\text { factories. }\end{array}$ & & $\mathrm{DL}$ \\
\hline Tieng et al. ID & S & As & Virtual metrology system for sampling. & 4 & $\begin{array}{l}\text { BPNN, PLS, } \\
\text { GA, IF }\end{array}$ \\
\hline $\begin{array}{l}\text { Vathoopan et al. HC } \\
\text { 2018. }\end{array}$ & $\mathrm{H}$ & ND & Corrective maintenance using the digital twin of an automation model. & 3 & DigT \\
\hline Kaupp et al. IP & $\mathrm{TL}$ & $\mathrm{Gl}$ & Outlier identification to measure the glass quality. & 5 & NN \\
\hline $\begin{array}{l}\text { Ventura et al. ID } \\
2019 \text {. }\end{array}$ & $\mathrm{S}, \mathrm{P}$ & ND & Automatic industrial equipment maintenance system. & 6 & $\begin{array}{ll}\mathrm{DS}, & \mathrm{SS}, \\
\mathrm{KMC} & \end{array}$ \\
\hline
\end{tabular}

\subsubsection{Predictive Analytics}

The practical applications that used Predictive Analytics techniques are shown in Table 9 Predictive Analytics involve a set of data-driven models that are typically obtained by applying supervised Machine Learning algorithms. Predictive Analytics are the most used techniques in the practical applications obtained for this SLR. For instance, some studies perform classification techniques Q. Cao, Zanni-Merk, Samet, De Bertrand de Beuvron, \& Reich 2020 Kiangala \& Wang2018 S. C. Li, Huang, Tai, \& Lin 2017 Miškuf \& Zolotová 2016 Sellami, Miranda, Samet, Bach Tobji, \& de Beuvron 2019, while other used regression techniques Calabrese et al.2020 Charest, Finn, \& Dubay|2018 |Peralta et al.2017 | Rousopoulou et al. 2019]. Simple neural networks are used in several research works such as Cisotto \& Herzallah 2018 Kabugo, Jämsä-Jounela, Schiemann, \& Binder 2020 Miškuf \& Zolotová 2016 Soto, Tavakolizadeh, \& Gyulai 2019 Spendla, Kebisek, Tanuska, \& Hrcka 2017. Other studies used more advanced Deep Learning Neural Networks Choi, Kim, Kim, \& Kim 2017 Essien \& Giannetti 2020 H. Kuo \& Faricha 2016 W. J. Lee et al.2019 Maggipinto, Terzi, Masiero, Beghi, \& Susto 2018. Furthermore, some of the surveyed Preditive Analytics used optimization techniques (e.g., Genetic Algorithm, Paticle Swarm Optimization) Rosli, Ain Burhani, \& Ibrahim 2019 Saldivar, Goh, Li, Chen, \& Yu 2016 Saldivar, Goh, Li, Yu, \& Chen 2016, while other works focused on outliers detection and statistical analysis Albers et al. 2017 Stein et al.|2016.

TABLE 9 Overview of the Practical Articles that used Predictive Analytics Techniques 


\begin{tabular}{|c|c|c|c|c|c|}
\hline Reference $\quad$ Func ${ }^{5}$ & Data $^{6}$ & Sector $^{7}$ & Goal & Impact & Modeling 8 \\
\hline $\begin{array}{l}\text { Kohlert and ID, PdM } \\
\text { König 2016. }\end{array}$ & & $\mathrm{PI}$ & $\begin{array}{l}\text { Human-machine-based process monitoring and control for yield optimiza- } \\
\text { tion in polymer film industry. }\end{array}$ & & $\begin{array}{l}\text { NN, SVM, } \\
\text { KNN, } \\
\text { NOVCLASS }\end{array}$ \\
\hline $\begin{array}{l}\text { H. Kuo and IP } \\
\text { Faricha 2016. }\end{array}$ & S & SC & Improve the accuracy of grating displacement offset prediction. & 4 & ANN \\
\hline $\begin{array}{l}\text { T. Lin, Chen, PdM } \\
\text { Yang, and Chen } \\
\text { 2016 }\end{array}$ & $\mathrm{S}$ & $\mathrm{Sp}$ & $\begin{array}{l}\text { Triaxial sensors to aid in machine monitoring to facilitate the transition of } \\
\text { data. }\end{array}$ & & $\begin{array}{l}\text { NN, SVM, } \\
\text { KNN, NFM }\end{array}$ \\
\hline $\begin{array}{l}\text { Miškuf and ID } \\
\text { Zolotová 2016 }\end{array}$ & $\mathrm{T}$ & ND & Multi-Class Classifiers and Deep Learning in the Industry 4.0 Context. & 4 & $\begin{array}{l}\text { NN, DF, DJ, } \\
\text { LogR, SVM, } \\
\text { h2oDL }\end{array}$ \\
\hline $\begin{array}{l}\text { Saldivar, Goh, ID } \\
\text { Chen, and Li } \\
\text { 2016. }\end{array}$ & CS & A & Developed a Predictive Analytics framework to add mass customization. & 3 & SOM \\
\hline $\begin{array}{l}\text { Saldivar, Goh, IP } \\
\text { Li, Yu, and Chen } \\
2016\end{array}$ & CM & A & Predict the decision-making and customize the intelligent product design. & & FL, GA \\
\hline $\begin{array}{l}\text { Saldivar, Goh, ID } \\
\text { Li, Chen, and Yu } \\
2016\end{array}$ & CS & $A$ & Predictive Analytics framework for the automotive area. & 4 & $\mathrm{GA}, \mathrm{KM}$ \\
\hline Stein et al. IP & $\operatorname{Pr}$ & A & $\begin{array}{l}\text { On-line process monitoring and predictive modeling to optimize the car } \\
\text { production process. }\end{array}$ & & GLOSS \\
\hline $\begin{array}{l}\text { Albers et al. ID } \\
2017 \text {. }\end{array}$ & Ac & ND & $\begin{array}{l}\text { Evaluate the product quality and tool defects by using an acoustic emission } \\
\text { sensor. }\end{array}$ & & ANOVA \\
\hline 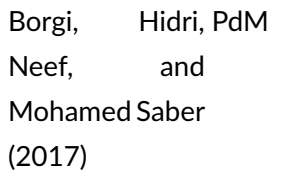 & $\mathrm{Rb}$ & ND & $\begin{array}{l}\text { Predictive maintenance of industrial robots using movements power } \\
\text { condition-monitoring. }\end{array}$ & & MSD, Sk, K \\
\hline Choi et al. ID & RM & ND & $\begin{array}{l}\text { Deep Learning to analyze and evaluate the performance of the Deep } \\
\text { Learning method. }\end{array}$ & & $\mathrm{DL}$ \\
\hline
\end{tabular}

\footnotetext{
${ }^{5}$ Hardware Connection (HC), Information Discovery (ID), Intelligent Production (IP), Predictive Maintenance (PdM)

${ }^{6}$ Acoustic (Ac), Car Manufacturing (CM), Car Specification (CS), Chemical (Ch), Chemical Laboratory (ChL), Gas Turbine (GT), Gesture Images (GI), Image (I), Machine (Mc), Machine Center (McC), Material (Ma), Network (N), Pellets Images (PI), Production (Pr), Reference Metadata (RM), Robotic (Rb), Sensor (S), Sheet Material (SM), Simulated Sensor (SimS), Solar Panel (SolP), Steel (St), Text (T), Time Series (TS), Welding Images (WI)

${ }^{7}$ Aerospacial (Ae), Automotive (A), Coil (C), Electronic (El), Energy (En), Food (Fo), Footwear (F), Furniture (Fu), Healthcare (Hc), Naval (Na), Not Disclosed (ND), Oil (O) Petrochemical (Pc), Polymer (PI), Robotic (Rb), Semiconductor (SC), Spring (Sp), Steel Plate (SP), Transportation (Tr),

${ }^{8}$ Adaptive Neuro-Fuzzy Inference Systems (ANFIS), Analysis of Variances (ANOVA), Artificial Neural Networks (ANN), Association Rules (AsR), Backtracking Search Optimization Algorithm (BSOA) Bagged Decision Trees (BDT), Bagged Trees (BagT), Bagging (Bag), Bayesian Filter (BF) Boosting Trees (BosT), Complex Fuzzy (CF), Conference Trees (CT), Convolutional Neural Networks (CNN), Decision Forest (DF), Decision Jungle (DJ), Decision Trees (DT), Deep Learning (DL), Density-Based Spatial Clustering of Applications with Noise (DBSCAN), Discriminant Analysis (DA), Extreme Gradient Boosting (EGB), Extreme Learning Machine Boundary (ELMB), Extremely Randomized Trees (ERT), Fast Nearest Neighbors (FaNN), Feed Forward Neural Network (FeNN), Fog Computing (FC), Fuzzy-Logic (FL), Gaussian Model (GM), Gaussian Noise (GN), Genetic Algorithm (GA), Genetic Programming Based Symbolic Regression (GPBSR), Global Local Outliers in Sub Spaces (GLOSS), Gradient Boosted Regression Trees (GBRT), Gradient Boosted Tree Classifier (GBTC), Gradient Boosting (GB), Gradient Boosting Decision Trees (GBDT), Gradient Boosting Machine (GBM), H20 Deep Learning (h2oDL), Hidden Gama Process-Particle Filter (HGP-PF), Hidden Markov (HM), In Situ Classification System (ISCS), Isolation Forest (IF), Kalman Filter (KF), Kurtosis (K), K-Means (KM), K-Nearest Neighbor (KNN), Linear and Polynomial Fit (LPF), Linear Regression (LinR), Local Outlier Factor (LOF), Logistic Regression (LogR), Map Reduce (MR), Matlab Model Predictive Toolbox (MMPT), Mean and Standard Deviation (MSD), Mean Shift (MS), Microsoft Azure Machine Learning (MAML), Micro-Cluster Continuous Outlier Detection (MCCOD), Model Predictive Controller (MPC), Multiple Regression (MR), Multivariate Adaptive Regression Splines (MARS), Multi-Entity Bayesian Networks Regression (MEBNR), Multi-Layer Regression (MLR), Naive Bayes (NB), Neural Networks (NN), Neuro-Fuzzy Networks (NFN), Noise Impulse Integration (NII), Novelty Classifier (NOVCLASS), Out-of-Bag Error (OBE), Partial Least Squares (PLS), Particle Swarm Optimization (PSO), Principal Component Analysis (PCA), Pure Quadratic Regression (PQR), Quadratic Discriminant Analysis (QDA), Random Forest (RF), Random Support Vector Machine (RSVM) Recursive Partitioning (RP), Regression Trees (RT), Ridge Regression (RR), Rule-Based (RB), Skewness (Sk), Spectral and Agglomerative Clustering (SAC), SRT Model (SRTM), Stochastic Model Predictive Controller (SMPC), Support Vector Machines (SVM) Survival Analysis (SA), Time Series Forecasting (TSF), ZeroR (ZR),
} 


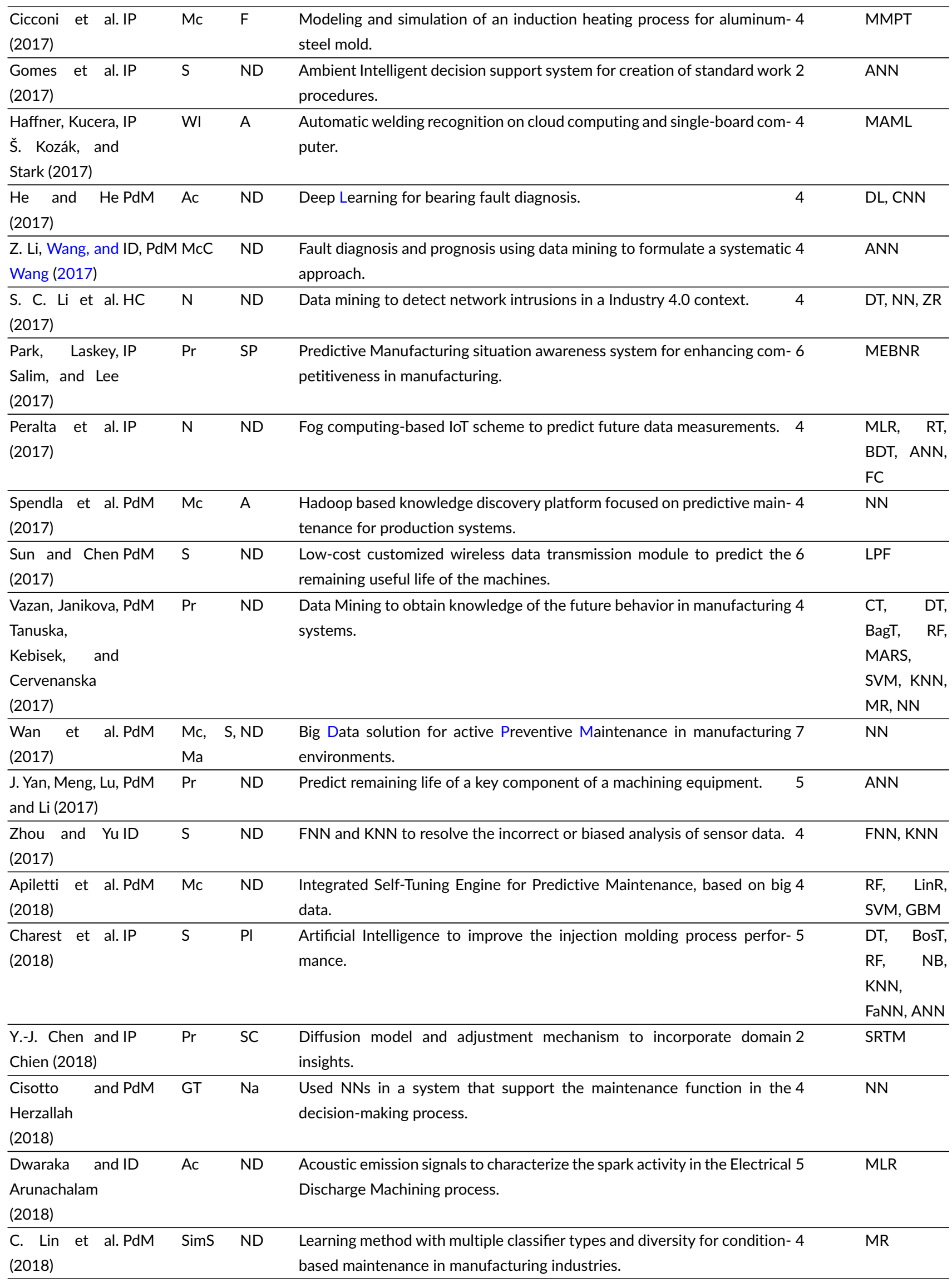




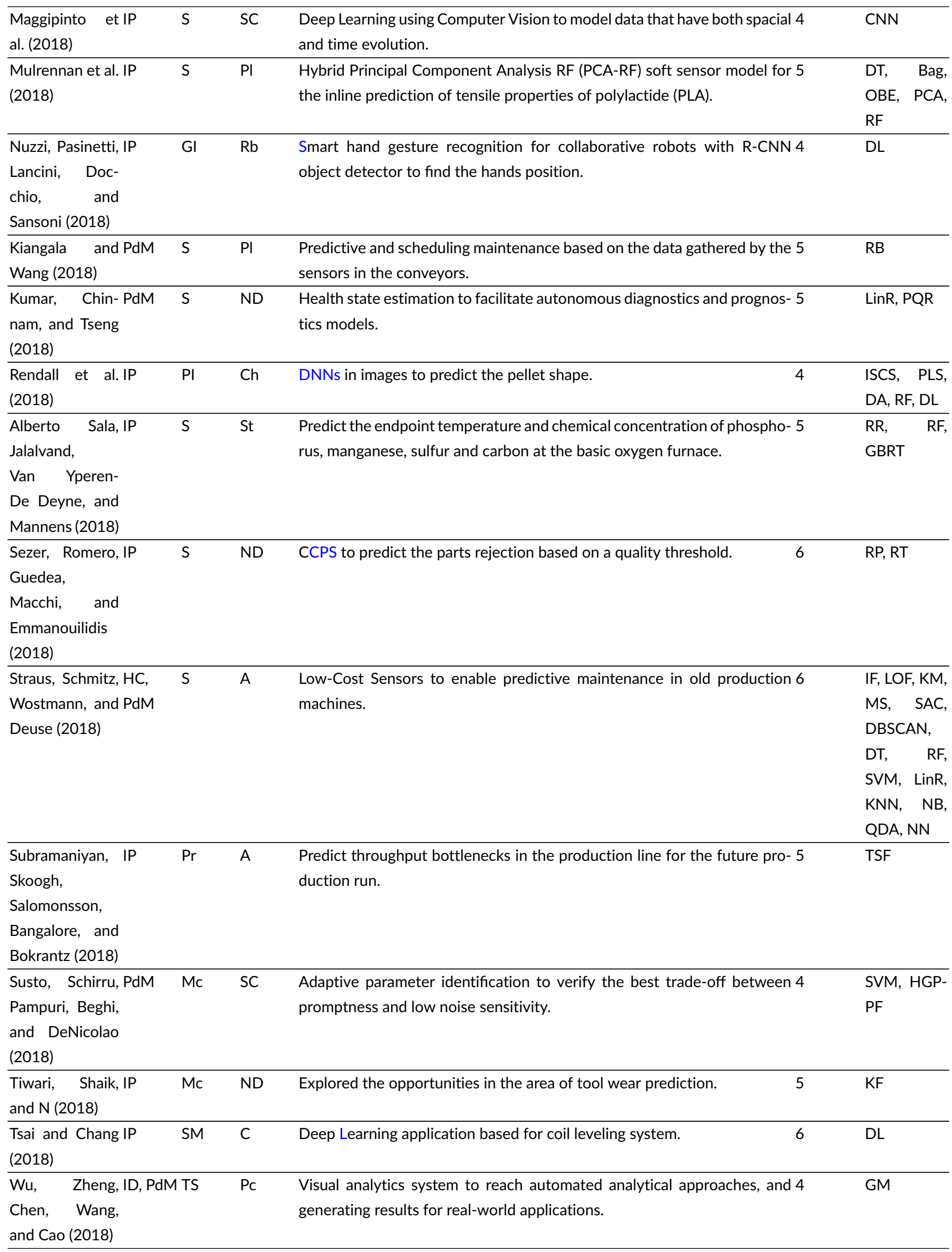




\begin{tabular}{|c|c|c|c|c|c|}
\hline H. Yan et al. & PdM & S & ND & $\begin{array}{l}\text { Device electrocardiogram and an deep denoising auto-encoder algorithm } 5 \\
\text { to predict the remaining useful life of the equipment. }\end{array}$ & $\mathrm{DL}$ \\
\hline $\begin{array}{l}\text { Antomarioni et } \\
\text { al. } 2019 \text {. }\end{array}$ & PdM & $\mathrm{Pr}$ & $\mathrm{O}$ & $\begin{array}{l}\text { Predict component breakages and determine the optimal set of compo- } 5 \\
\text { nents to repair. }\end{array}$ & AsR \\
\hline $\begin{array}{l}\text { Akhtari, } \\
\text { hardt, } \\
\text { Di Pietro, } \\
\text { Tomarchio } \\
\text { 2019 } \\
\end{array}$ & & $\mathrm{S}$ & $\operatorname{Tr}$ & DNN to detect and classify the load on a power-train. & $\mathrm{DL}$ \\
\hline $\begin{array}{l}\text { Aydemir and } \\
\text { Paynabar 2019 }\end{array}$ & PdM & I & ND & $\begin{array}{l}\text { Deep Learning methods for estimating time-to-failure of and industrial } 5 \\
\text { system using its degradation image. }\end{array}$ & $\mathrm{DL}$ \\
\hline $\begin{array}{l}\text { Bousdekis et al. } \\
2019 \text {. }\end{array}$ & PdM & $\mathrm{S}$ & St & Predictive Maintenance architecture according to RAMI 4.0. & NN, DL, HM \\
\hline $\begin{array}{l}\text { Bose, Kar, Roy, } \\
\text { Gopalakrishnan, } \\
\text { and Basu 2019 }\end{array}$ & PdM & Mc & $\mathrm{Ae}$ & $\begin{array}{l}\text { Anomaly Detection based Power Saving (ADEPOS) scheme using Extreme } 4 \\
\text { Learning Machine Boundary through the lifetime of the machine. }\end{array}$ & ELMB \\
\hline $\begin{array}{l}\text { Bruneo and De } \\
\text { Vita 2019. }\end{array}$ & PdM & Mc & $\mathrm{Ae}$ & $\begin{array}{l}\text { Deep Learning to analyze the history of a system to predict the Remaining } 4 \\
\text { Useful Life. }\end{array}$ & $\mathrm{DL}$ \\
\hline $\begin{array}{l}\text { Candanedo, } \\
\text { González, De la } \\
\text { Prieta, and } \\
\text { Arrieta 2019 } \\
\end{array}$ & PdM & S & $\operatorname{Tr}$ & Predict failures in Air Pressure System in trucks. & KNN, NB \\
\hline $\begin{array}{l}\text { Hesser and } \\
\text { Markert 2019 }\end{array}$ & & S & ND & ANN to monitor the tool wear in retrofitted $\mathrm{CNC}$ milling machines. & ANN \\
\hline $\begin{array}{l}\text { W. J. Lee et al. } \\
2019 \text {. }\end{array}$ & PdM & $\operatorname{Pr}$ & ND & $\begin{array}{l}\text { Predictive Maintenance to monitor two machine tool system elements, the } 5 \\
\text { cutting tool, and the spindle motor. }\end{array}$ & SVM, DL \\
\hline Liulys 2019 & PdM & $\mathrm{S}$ & El & $\begin{array}{l}\text { Open-source software to develop predictive maintenance applications } 3 \\
\text { with basic programming knowledge. }\end{array}$ & GBM, NN \\
\hline $\begin{array}{l}\text { Massaro, } \\
\text { Manfredonia, } \\
\text { Galiano, and } \\
\text { Xhahysa 2019 } \\
\end{array}$ & IP & $\operatorname{Pr}$ & $\mathrm{Fu}$ & ANN to predict the product defects in a kitchen manufacturing Industry. 5 & ANN \\
\hline $\begin{array}{l}\text { Massaro, } \\
\text { Manfredonia, } \\
\text { Galiano, Pelli- } \\
\text { cani, and Birardi } \\
2019 \\
\end{array}$ & IP & $\mathrm{S}$ & Fo & Predict the humidity during the pasta production. & ANN \\
\hline \begin{tabular}{|l|} 
Martinek and \\
Krammer 2019
\end{tabular} & & I & $\mathrm{El}$ & $\begin{array}{l}\text { Machine Learning based prediction methods to optimize the process } 5 \\
\text { parameters of pin-in-paste. }\end{array}$ & $\begin{array}{l}\text { ANN, } \\
\text { ANFIS, } \\
\text { GBDT }\end{array}$ \\
\hline \begin{tabular}{|l|} 
Packianather, \\
Munizaga, \\
Zouwail, and \\
Saunders 2019
\end{tabular} & PdM & ChL & $\mathrm{Hc}$ & $\begin{array}{l}\text { Three phase methodology to automate quality control in healthcare clini- } 5 \\
\text { cal laboratory. }\end{array}$ & KNN \\
\hline $\begin{array}{l}\text { Pinto and } \\
\text { Cerquitelli } \\
2019 \\
\end{array}$ & PdM & $\mathrm{S}$ & $\mathrm{Rb}$ & Predict the fault detection and remaining life estimation of robots. & $\begin{array}{l}\text { SA, ERT, } \\
\text { KNN, CNN }\end{array}$ \\
\hline Plehiers et al. & & $\mathrm{S}$ & $\mathrm{Ch}$ & $\begin{array}{l}\text { Framework for chemical production in process-steam cracking to optimize } 4 \\
\text { the process control. }\end{array}$ & ANN \\
\hline
\end{tabular}




\begin{tabular}{|c|c|c|c|c|}
\hline $\begin{array}{l}\text { Proto et al. IP } \\
2019 \text {. }\end{array}$ & $\mathrm{S}$ & $\mathrm{Ch}$ & $\begin{array}{l}\text { PREdictive Maintenance service for Industrial procesSES (PREMISES) to } 6 \\
\text { predict alarms in slowly-degrading multi-cycle industrial process. }\end{array}$ & GBTC, RF \\
\hline $\begin{array}{l}\text { Rogier and IP } \\
\text { Mohamudally } \\
2019 \text {. } \\
\end{array}$ & SolP & En & NN to predict the conversion of solar energy by a photovoltaic unit. & NN \\
\hline Rosli et al. PdM & $\mathrm{S}$ & SC & Preventive maintenance for air booster compressor motor failure. & ANN, PSO \\
\hline $\begin{array}{l}\text { Rousopoulou et PdM } \\
\text { al. 2019. }\end{array}$ & $\operatorname{Pr}$ & $\mathrm{Hc}$ & Predictive analytics for industrial ovens in the healthcare industry. & SVM \\
\hline Sellami et al. PdM & Mc & SC & $\begin{array}{l}\text { Predict machine failures and presented an algorithm for frequent chroni- } 4 \\
\text { cles extraction. }\end{array}$ & Clasp-CPM \\
\hline Soto et al. PdM & $\mathrm{S}$ & ND & $\begin{array}{l}\text { loT Machine Learning and orchestration to failure detection of surface } 4 \\
\text { mount devices during production. }\end{array}$ & $\mathrm{NN}, \mathrm{RF}, \mathrm{GB}$ \\
\hline $\begin{array}{l}\text { Naskos, } \\
\begin{array}{|l|}\text { Gounaris, } \\
\text { Metaxa, and } \\
\text { Köchling 2019 } \\
\end{array}\end{array}$ & Mc & $\mathrm{O}$ & $\begin{array}{l}\text { Predictive Maintenance with applied unsupervised Machine Learning } 5 \\
\text { techniques to detect early oil leaks. }\end{array}$ & MCCOD \\
\hline $\begin{array}{l}\text { Zenisek, Wol-PdM } \\
\text { fartsberger, } \\
\text { Sievi, and } \\
\text { Affenzeller } \\
\text { 2019, }\end{array}$ & $\mathrm{S}$ & ND & $\begin{array}{l}\text { Machine Learning algorithms to detect changing behavior to enhance the } 3 \\
\text { maintenance on a microscopic level. }\end{array}$ & $\begin{array}{l}\text { RF, SVM, } \\
\text { GPBSR }\end{array}$ \\
\hline $\begin{array}{l}\text { T. Zhang, Feng, IP } \\
\text { and Hao 2019. }\end{array}$ & $\operatorname{Pr}$ & $\mathrm{El}$ & Random-SVM (R-SVM) to predict the quality of the TFT-LCD liquid. & RSVM \\
\hline $\begin{array}{l}\text { Alasali, Haben, IP } \\
\text { Foudeh, and } \\
\text { Holderbaum } \\
2020 \text {. }\end{array}$ & Mc & $\operatorname{Tr}$ & $\begin{array}{l}\text { Predict the stochastic loads to improve the performance of a low voltage } 6 \\
\text { network. }\end{array}$ & $\begin{array}{l}\text { MPC, } \\
\text { SMPC }\end{array}$ \\
\hline Calabrese et al. PdM & Mc & $\mathrm{Fu}$ & $\begin{array}{l}\text { Machine Learning to predict the health status of a woodworking industrial } 6 \\
\text { machine. }\end{array}$ & GB, RF, EGB \\
\hline Q. Cao et al. PdM & $\operatorname{Pr}$ & ND & Rule-based refinement approach for detect and predict anomalies. & RB \\
\hline $\begin{array}{l}\text { Essien and IP } \\
\text { Giannetti } 2020 \text {. }\end{array}$ & Mc & ND & $\begin{array}{l}\text { Deep Learning model for univariate, multi-step machine speed forecasting } 4 \\
\text { in a manufacturing process. }\end{array}$ & DL \\
\hline Kabugo et al. IP & $\operatorname{Pr}$ & En & $\begin{array}{l}\text { Predict syngast heating value and hot flue gas temperature from data } 5 \\
\text { obtained from soft sensors. }\end{array}$ & NN \\
\hline $\begin{array}{l}\text { Karakose and PdM } \\
\text { Yaman 2020 }\end{array}$ & $\mathrm{S}$ & $\operatorname{Tr}$ & $\begin{array}{l}\text { Fuzzy system-based approach for Predictive Maintenance on electric } 4 \\
\text { railways. }\end{array}$ & $\mathrm{CF}$ \\
\hline $\begin{array}{l}\text { Kim, Lee, IP } \\
\text { Adhi Tama, and } \\
\text { Lee 2020 } \\
\end{array}$ & $\operatorname{Pr}$ & ND & $\begin{array}{l}\text { Predict the state of an unseen camera lens module using semi-supervised } 5 \\
\text { regression. }\end{array}$ & $\mathrm{DL}$ \\
\hline $\begin{array}{l}\text { Ruiz-Sarmiento PdM } \\
\text { et al. } 2020\end{array}$ & $\operatorname{Pr}$ & SP & Estimate and predict the gradual degradation of production machines. & $\mathrm{BF}$ \\
\hline $\begin{array}{l}\text { de Sá, Casimiro, HC } \\
\text { Machado, and } \\
\text { Carmo 2020 }\end{array}$ & $\operatorname{Pr}$ & ND & Metaheuristics to identify data injection attacks by man-in-the-middle. 4 & $\begin{array}{l}\text { BSOA, GN, } \\
\text { NII }\end{array}$ \\
\hline
\end{tabular}




\subsubsection{Prescriptive Analytics}

The last table of this SLR (Table 10 presents the practical cases that used Prescriptive Analytics. These types of analytics aims to describe what courses of action may be taken in the future to optimize business processes in order to achieve business objectives. Typically, this is achieved by associating decision alternatives (or choices) with estimated business outcomes. A diverse set of modeling tools can be used to obtain such analytics, namely optimization and simulation, design experimentation and scenario scheduling Banerjee, Bandyopadhyay, \& Acharya 2013. Jugulum 2016.

The majority of the surveyed studies used optimization techniques. In particular, the most explored method was the Genetic Algorithm Khayyam et al.2019 Silva, Jesus, Villaverde, \& Adina 2020. Other authors Ansari, Glawar, \& Nemeth2019 Brik, Bettayeb, Sahnoun, \& Duval 2019 Fu, Ding, Wang, \& Wang 2018 H. Li|2016 Qu, Wang, Govil, \& Leckie 2016 Tsourma, Zikos, Drosou, \& Tzovaras 2018 Uriarte, Ng, \& Moris 2018, employed other optimization techniques, such as [Tsourma et al. 2018 that proposed a Task Distribution Engine to automate and optimize the task scheduling and resources assignment procedure in industrial environments. We also found studies that performed Prescriptive Analytics by using predictive models to directly perform actions: Deep Learning (Richter, Streitferdt, \& Rozova 2017; Regression Trees and Nearest Neighbors Romeo, Paolanti, Bocchini, Loncarski, \& Frontoni 2018; and SVM combined with Q-Learning Qu et al.2016.

\section{5 | DISCUSSION}

Figure 3 presents the Literature Map resulted from this SLR. This Literature Map contains three different levels of interactions, where the first level is the Analytics Level and the second level contains the components of the different Analytics application levels (Data Visualization, Detect Production Anomalies, Improve Product Quality, Detect Costumers Needs, Predictive Maintenance and Resources Optimization). The last level presents the different techniques used for each component, as well as some studies that use these techniques. To simplify the visualization, the map only details business analytics techniques that were used in two or more practical cases.

It is clear in Figure 3 that Supervised Learning techniques (Classification and Regression algorithms) are a popular approach of Business Analytics in Industry 4.0, being adopted in all the application types identified in this SLR. Statistical Data Analysis is a technique used mainly for Data Visualization, but it was also used for Predictive Maintenance (Mozgova et al. 2018, to Detect Anomalies in Production [heng \& Wu 2017] and to Improve Product Quality Kirchen et al.2017. Clustering is a more advanced technique compared to Statistical Data analysis, and is used to find Production Anomalities Y. Wang et al. 2017], to improve the products quality T. Lin et al. 2016], to detect costumers needs Saldivar, Goh, Li, Yu, \& Chen 2016, and for predictive maintenance (Candanedo et al. 2019. Reinforcement Learning was used mostly for Resources Optimization Pane, Nageshrao, Kober, \& Babuska 2019 Qu et al. 2016, while Optimization techniques were used for Resources Optimization Uriarte et al. 2018, to Detect Production Anomalies (Trunzer et al. 2017) and to Improve Product Quality (Khayyam et al. 2019.

Regarding the Supervised Learning techniques, based on Classification and Regression algorithms, it is important to mention the popularity of Neural Networks (in their ANN, DL, or CNN forms), in the different Industry 4.0 areas. In effect, the use of Neural Networks reaches every area of application studied in this SLR with a total of 38 practical applications retrieved in this study. Moreover, the use of Neural Networks is growing over the time, with 4 applications in 2016, 10 in 2017, 7 in 2018, 14 in 2019, and 3 applications in the first months of 2020.

The Literature Map from Figure 3 provides a general overview of the different application areas of Business Analytics in Industry 4.0, where it is clear that the areas of Improve Product Quality, Anomalies Detection and Predictive Maintenance are the most popular. While Business Analytics techniques can also be employed to optimize resources in the Industry or to Detect Costumers Needs, a small number of research application studies have addressed these topics, with 9 applications focused on Resources Optimization and 4 applications in Detect Costumer Needs.

\section{CONCLUSIONS AND RESEARCH IMPLICATIONS}

This paper presents the results of a Systematic Literature Review (SLR) to analyze the evolution and the application of Business Analytics techniques in the Industry 4.0 context. As stated in Section 1 the Research Question targeted by this SLR research is: How and in what areas of the industry are Business Analytics techniques being used in an Industry 4.0 context? The papers were surveyed by performing an initial keywords query on scientific search engines. Then, the retrieved papers were manually inspected by performing a careful analysis, to assure that the most relevant studies for this SLR were selected. Next, we have analyzed the selected papers in terms of both quantitative and qualitative elements. The quantitative analysis showed that the most published type of paper is the Practical Application. As for the quantitative analysis, it consisted in a characterization of the Descriptive, Predictive and Prescriptive analytics in terms of what types of applications are implemented in the Industry, what are the techniques used in the practical applications and the impact of the results achieved. Considering the presented SLR we highlight that: 


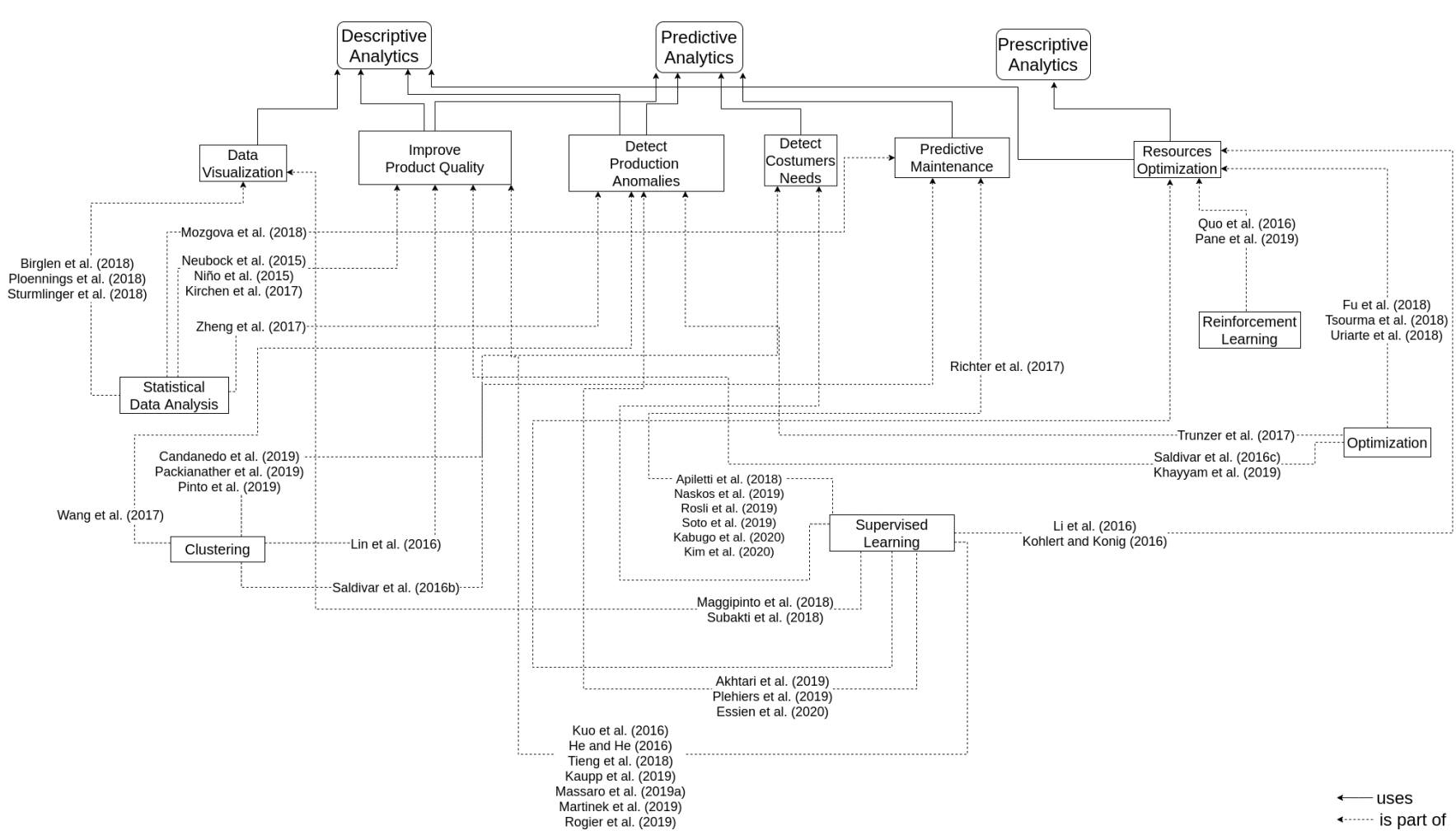

FIGURE 3 Literature Map

TABLE 10 Overview of the Practical Articles that used Prescriptive Analytics Techniques

\begin{tabular}{|c|c|c|c|c|c|}
\hline Reference & Func 9 & Dat: ${ }^{10}$ & Sector ${ }^{11}$ & Impact & Modeling ${ }^{12}$ \\
\hline H. Li 2016. & IP & Co & ND & $\begin{array}{l}\text { Classification algorithm and Q-learning algorithm to reduce the electricity } 4 \\
\text { consumption in an automation system. }\end{array}$ & SVM, QL \\
\hline Qu et al. 2016 & IP & $\operatorname{Pr}$ & ND & $\begin{array}{l}\text { Synchronized, station-based flow shop with multi-skill workforce and } 3 \\
\text { multiple types of machines. }\end{array}$ & $\begin{array}{l}\text { RL, MARL, } \\
\text { Op }\end{array}$ \\
\hline $\begin{array}{l}\text { Klement and } \\
\text { Silva 2017. }\end{array}$ & & $\operatorname{Pr}$ & $\mathrm{PI}$ & $\begin{array}{l}\text { Hybrid approach with List Algorithm and Metaheuristic to optimize plan- } 3 \\
\text { ning, assignment, scheduling and lot sizing. }\end{array}$ & LA, SA \\
\hline Richter et al. & IP & Mc & $\mathrm{El}$ & $\begin{array}{l}\text { Optimization techniques for the manufacturers and users of } \mathrm{AOI} 2 \\
\text { machines. }\end{array}$ & $\mathrm{DL}$ \\
\hline $\begin{array}{l}\text { Bányai, Illés, and } \\
\text { Bányai 2018 }\end{array}$ & $\mathrm{HC}$ & $\mathrm{Ge}$ & $\operatorname{Tr}$ & Black Hole Optimization for first mile and last mile supply. & $\mathrm{BHO}$ \\
\hline Fu et al. 2018. & IP & In & ND & $\begin{array}{l}\text { Two-objective stochastic flow-shop deteriorating and learning scheduling } 4 \\
\text { problem for advanced intelligent machines. }\end{array}$ & $\mathrm{MOO}, \mathrm{FA}$ \\
\hline
\end{tabular}

\footnotetext{
${ }^{9}$ Hardware Connection (HC), Information Discovery (ID), Intelligent Production (IP), Predictive Maintenance (PdM)

${ }^{10}$ Conveyor (Co), Geospatial (Ge), Industrial (In), Machine (Mc), Network (N), Production (Pr), Sensor (S)

${ }^{11}$ Automotive (A), Chemical (Ch), Electronic (El), Lean (Le), Mechanical (MC), Not Disclosed (ND), Polymer (PI), Transportation (Tr)

${ }^{12}$ Artificial Neural Networks (ANN), Black Hole Optimization (BHO), Constrained Optimization (CO), Coyote Optimization Algorithm (COA), Crow Search Algorithm (CSA), Decision Trees (DT), Deep Learning (DL), Fireworks Algorithm (FA), Fog Computing (FC), Genetic Algorithm (GA), Global Cheapest Arc (GCA), Grey Wolf Optimizer (GWO), Guided Local Search (GLS), Iterative Local Search (ILS), K-Nearest Neighbor (KNN), List Algorithm (LA), Memetic Algorithm (MmA), Mixed Integer Linear Programming Model (MILPM), Multi-Agent Reinforcement Learning (MARL), Multiple-layer perceptron neural network (MLPNN), Multi-Objective Optimization (MOO), Neighborhood Component Feature Selection (NCFS), Optimization (Op), Particle Swarm Optimization (PSO), Path Cheapest Arc Savings (PCAS), Prescriptive Maintenance Model (PriMa), Q-Learning (QL), Random Forest (RF), Regression Trees (RT), Reinforcement Learning (RL), Self Organizing Migrating Algorithm (SOMA), Simplified Swarn Optimization (SSO), Simulated Annealing (SA), Simulated Annealing Tabu Search (SATS), Simulation-based Multi-Objective Optimization (SBMOO), Support Vector Machines (SVM), Tabu Search (TbS), Variable Neighborhood Descent Based (VNDB), Variable Neighborhood Search (VNS), Whale Optimization Algorithm (WOA)
} 


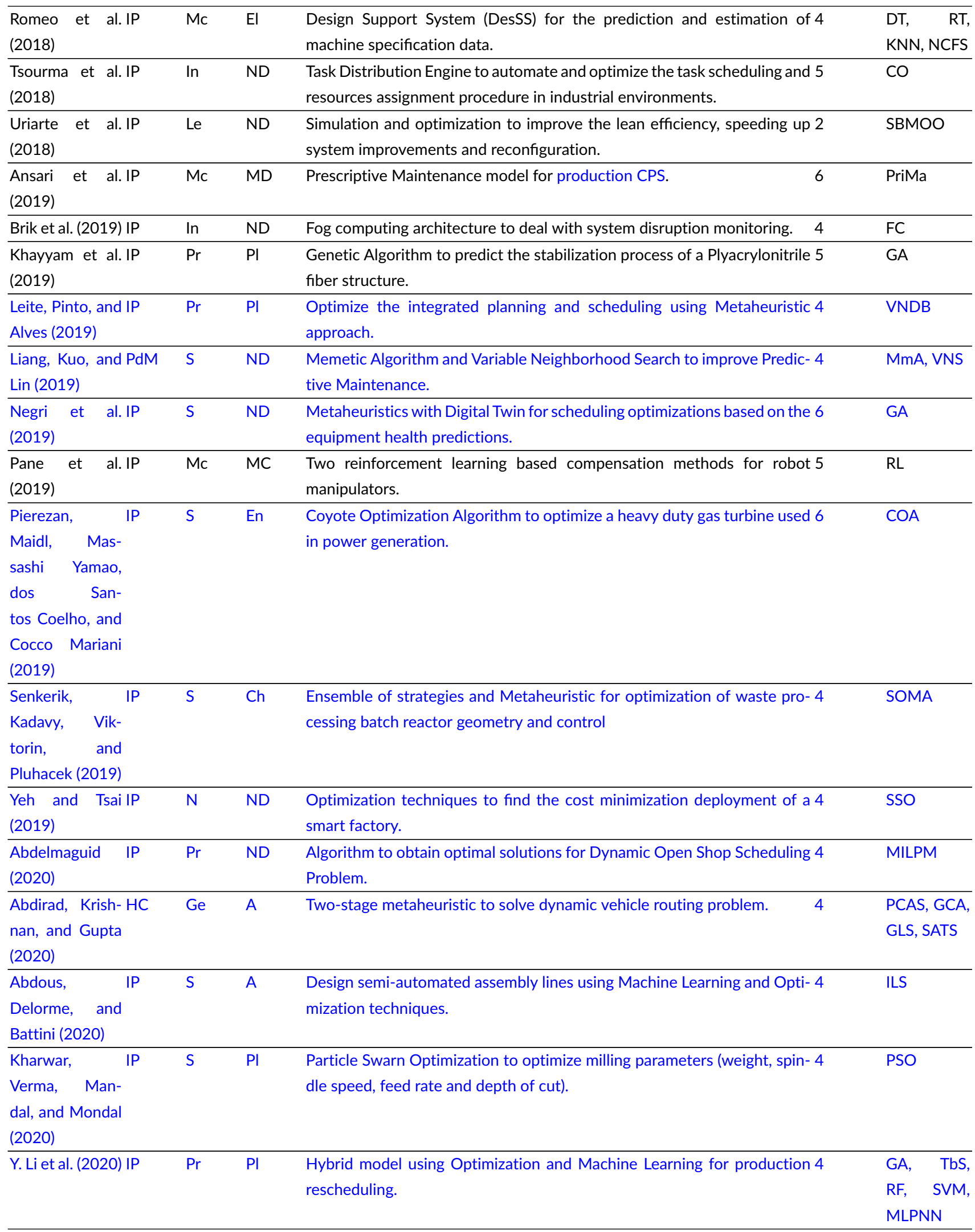




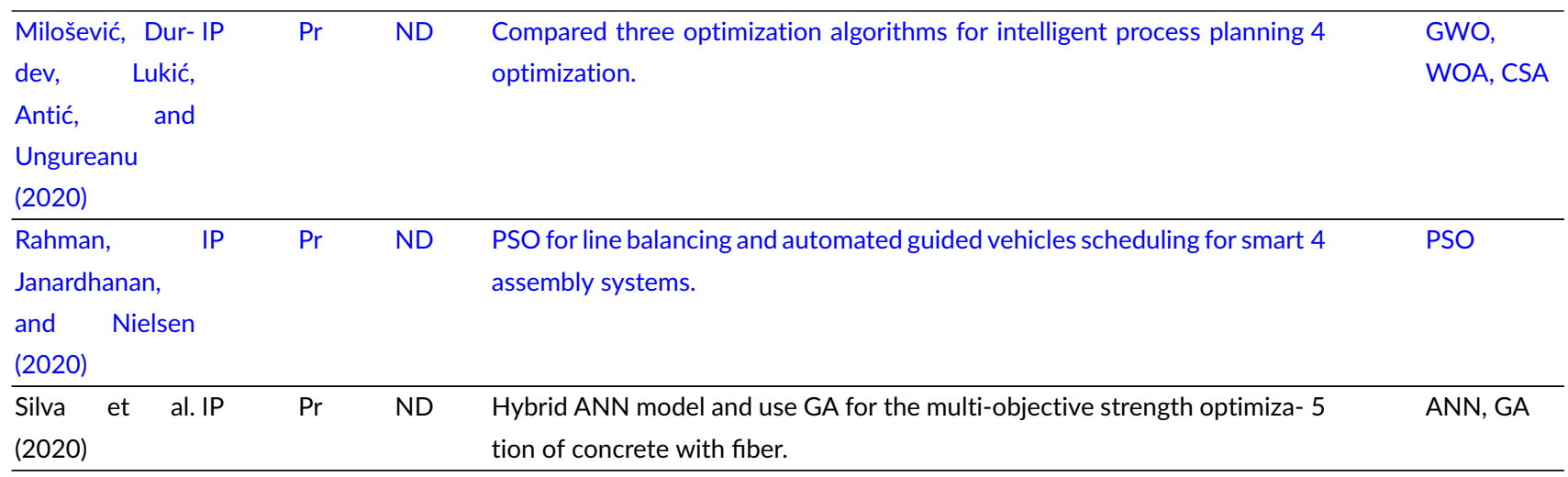

- The application of Business Analytics techniques within the Industry 4.0 concept has grown in recent years and its popularity is still rising (as shown in Figure 1 and Table 6. Thus, there is a research opportunity for publishing more papers regarding Business Analytics applied to the Industry 4.0.

- Manufacturing is the industry sector with the most practical applications (Table 5. One contributing factor for this phenomenon is that there has been a financial support for the adoption of innovative manufacturing techniques European Commission 2013. Nevertheless, there is a research opportunity set in terms of addressing other industry sectors, such as Transportation or Construction.

- Within the manufacturing sector, most of the practical applications focused on problems existing in production lines, with different goals, such as detecting faults in production components, defective products, until monitoring the production process and optimization of productive components such as energy consumption and resources allocation.

- Regarding the type of analytics, Descriptive Analytics involved a total of 23 practical applications, Predictive Analytics with 80 application studies and Prescriptive Analytics included 24 research works. The popularity of Predictive Analytics is being linked with the growing interest in the fields of Machine Learning and Data Science in the decade of 2010 C. Costa \& Santos 2017.

- Regarding the modeling techniques used, Supervised Learning was the most used approach, with Neural Networks being used in 39 applications, Random Forest in 10 applications, Support Vector Machine in 6 applications, Decision Tree in 5 applications and Rule-Based in 2 applications. Classical Statistical Data Analysis was used in 11 applications, Clustering was addressed in 6 applications, the same number as Optimization techniques, and Reinforcement Learning was employed in 2 applications. Given the current success of the Deep Learning field Goodfellow, Bengio, Courville, \& Bengio 2016, it is expected that the number of Industry 4.0 research works that use Neural Networks will further increase in the future.

- Practical applications that use Descriptive Analytics are focused on analyzing the data obtained in order to find answers for diverse problems, such as verifying the tool wear through the time or what is the most common cause that leads to the equipment failure.

- The practical applications that used Predictive Analytics were more focused in Predictive Maintenance, such as predict when the equipment will fail, or verify if the equipment is not corresponding in terms of its typical performance.

- Practical applications that use Prescriptive Analytics target more on resources optimization, such as optimize the energy consumption or optimize the resources scheduling. However, the SLR results reveal that there is still a scarce number of research studies that use Prescriptive Analytics techniques within the Industry 4.0. Therefore, there is a huge potential for future research on more Prescriptive Analytics studies since there is a large number of industrial needs that are related with resource optimization and scheduling. Moreover, as pointed out by Davenport 2013, these are the analytics "that tell you what to do" and thus hold a higher business value by providing an actionable knowledge for the industry. Thus, in future works, we believe there will be an increase of Prescriptive Analytics applications for the Industry 4.0.

This SLR reviewed research papers published in the last decade (from 2010 to 2020). In the next decade, it is expected that Business Analytics will be more prevalent in the Industry, due to further advances in Artificial Intelligence (AI) and Machine Learning. In particular, as the European Commission plans a future investment of 7.5 Billion EUR in the areas of Advanced Computing and Artificial Intelligence Commission 2020, several of these funds will be devoted to Industry applications, which surely will be reflected in an increased number of research papers. 


\section{CONFLICT OF INTEREST}

The authors declare no conflict of interest.

\section{ACKNOWLEDGEMENTS}

The work of P. Cortez was supported by FCT - Fundação para a Ciência e Tecnologia within the R\&D Units Project Scope: UIDB/00319/2020. We would like to thank to the three anonymous reviewers for their helpful suggestions.

References

Abdelmaguid, T. (2020). Bi-objective dynamic multiprocessor open shop scheduling: An exact algorithm. Algorithms, 13(3). doi: 10.3390/a13030074

Abdirad, M., Krishnan, K., \& Gupta, D. (2020). A two-stage metaheuristic algorithm for the dynamic vehicle routing problem in Industry 4.0 approach. Journal of Management Analytics, 8(1), 69-83. doi: 10.1080/23270012.2020.1811166

Abdous, M.-A., Delorme, X., \& Battini, D. (2020). Cobotic Assembly Line Design Problem with Ergonomics. In L. M. Camarinha-Matos, H. Afsarmanesh, \& A. Ortiz (Eds.), Boosting collaborative networks 4.0 (pp. 573-582). Cham: Springer International Publishing.

Akhtari, S., Pickhardt, F., Pau, D., Di Pietro, A., \& Tomarchio, G. (2019). Intelligent embedded load detection at the edge on industry 4.0 powertrains applications. In 5th International Forum on Research and Technologies for Society and Industry: Innovation to Shape the Future, RTSI 2019 Proceedings (p. 427-430). Institute of Electrical and Electronics Engineers Inc. doi: 10.1109/RTSI.2019.8895598

Alasali, F., Haben, S., Foudeh, H., \& Holderbaum, W. (2020, May). A comparative study of optimal energy management strategies for energy storage with stochastic loads. Energies, 13, 2596. doi: 10.3390/en13102596

Albers, A., Stürmlinger, T., Wantzen, K., Bartosz, Gladysz, \& Münke, F. (2017). Prediction of the product quality of turned parts by real-time acoustic emission indicators. Procedia CIRP, 63, 348 - 353. Manufacturing Systems 4.0 - Proceedings of the 50th CIRP Conference on Manufacturing Systems. doi: 10.1016/j.procir.2017.03.173

Alberto Sala, D., Jalalvand, A., Van Yperen-De Deyne, A., \& Mannens, E. (2018, December). Multivariate time series for data-driven endpoint prediction in the basic oxygen furnace. In 17th IEEE International Conference on Machine Learning and Applications (ICMLA) (p. 1419-1426). Orlando, FL, USA: IEEE. doi: 10.1109/ICMLA.2018.00231

Ali, S., Qaisar, S. B., Saeed, H., Khan, M. F., Naeem, M., \& Anpalagan, A. (2015). Network challenges for cyber physical systems with tiny wireless devices: A case study on reliable pipeline condition monitoring. Sensors, 15(4), 7172-7205. doi: 10.3390/s150407172

Ansari, F., Glawar, R., \& Nemeth, T. (2019). Prima: a prescriptive maintenance model for cyber-physical production systems. International Journal of Computer Integrated Manufacturing, 32(4-5), 482-503. doi: 10.1080/0951192X.2019.1571236

Antomarioni, S., Pisacane, O., Potena, D., Bevilacqua, M., Ciarapica, F. E., \& Diamantini, C. (2019, December). A predictive association rule-based maintenance policy to minimize the probability of breakages: application to an oil refinery. The International Journal of Advanced Manufacturing Technology, 105. doi: 10.1007/s00170-019-03822-y

Apiletti, D., Barberis, C., Cerquitelli, T., Macii, A., Macii, E., Poncino, M., \& Ventura, F. (2018, December). istep, an integrated self-tuning engine for predictive maintenance in industry 4.0. In IEEE Int. Conf. on Parallel Distributed Processing with Applications, Ubiquitous Computing Communications, Big Data Cloud Computing, Social Computing Networking, Sustainable Computing Communications (ISPA/IUCC/BDCloud/SocialCom/SustainCom) (p. 924-931). Melbourne, Australia: IEEE. doi: 10.1109/BDCloud.2018.00136

Armbrust, M., Fox, A., Griffith, R., Joseph, A. D., Katz, R., Konwinski, A., ... Zaharia, M. (2010, April). A view of cloud computing. Commun. ACM, 53(4), 50-58. doi: 10.1145/1721654.1721672

Arnott, D., \& Pervan, G. (2014, December). A critical analysis of decision support systems research revisited: the rise of design science. Journal of Information Technology, 29(4), 269-293. doi: 10.1057/jit.2014.16

Aydemir, G., \& Paynabar, K. (2019). Image-based prognostics using deep learning approach. IEEE Transactions on Industrial Informatics, 16(9), 5956-5964.

Bagheri, M., Zollanvari, A., \& Nezhivenko, S. (2018). Transformer fault condition prognosis using vibration signals over cloud environment. IEEE Access, 6, 9862-9874. doi: 10.1109/ACCESS.2018.2809436

Bakar, N., Ramli, M., Sin, T., \& Masran, H. (2019). A review on Robotic assembly line balancing and metaheuristic in manufacturing industry. AIP Conference Proceedings, 2138. doi: 10.1063/1.5121084 
Banerjee, A., Bandyopadhyay, T., \& Acharya, P. (2013). Data analytics: Hyped up aspirations or true potential? Vikalpa, 38(4), 1-12. doi: $10.1177 / 0256090920130401$

Bányai, T., Illés, B., \& Bányai, A. (2018). Smart scheduling: An integrated first mile and last mile supply approach. Complexity, 2018. doi: $10.1155 / 2018 / 5180156$

Barton, D., \& Court, D. (2012, October). Making advanced analytics work for you. Harvard business review, 90, 78-83, 128.

Birglen, L., \& Schlicht, T. (2018). A statistical review of industrial robotic grippers. Robotics and Computer-Integrated Manufacturing, 49,88 - 97. doi: 10.1016/j.rcim.2017.05.007

BMBF. (2011). Industrie 4.0 - bmbf. Retrieved from https://www.bmbf .de/de/zukunftsprojekt-industrie-4-0-848.html Acessed: 2019-1229.

Bordel, B., \& Alcarria, R. (2017). Assessment of human motivation through analysis of physiological and emotional signals in industry 4.0 scenarios. Journal of Ambient Intelligence and Humanized Computing, 9, 1-21. doi: 10.1007/s12652-017-0664-4

Bordeleau, F.-E., Mosconi, E., \& Santa-Eulalia, L. A. (2018). Business intelligence in industry 4.0: State of the art and research opportunities. In Proceedings of the 51st hawaii international conference on system sciences. doi: 10.24251/HICSS.2018.495

Borgi, T., Hidri, A., Neef, B., \& Mohamed Saber, N. (2017, January). Data analytics for predictive maintenance of industrial robots. In 2017 international conference on advanced systems and electric technologies (ic aset) (p. 412-417). doi: 10.1109/ASET.2017.7983729

Bose, S. K., Kar, B., Roy, M., Gopalakrishnan, P. K., \& Basu, A. (2019). Adepos: Anomaly detection based power saving for predictive maintenance using edge computing. In Proceedings of the 24th asia and south pacific design automation conference (pp. 597-602). New York, NY, USA: ACM. doi: 10.1145/3287624.3287716

Bousdekis, A., Lepenioti, K., Ntalaperas, D., Vergeti, D., Apostolou, D., \& Boursinos, V. (2019). A rami 4.0 view of predictive maintenance: Software architecture, platform and case study in steel industry. In H. A. Proper \& J. Stirna (Eds.), Advanced information systems engineering workshops (pp. 95-106). Cham: Springer International Publishing. doi: 10.1007/978-3-030-20948-3_9

Brik, B., Bettayeb, B., Sahnoun, M., \& Duval, F. (2019). Towards predicting system disruption in industry 4.0: Machine learning-based approach. In S. E. (Ed.), (Vol. 151, p. 667-674). Elsevier B.V. doi: 10.1016/j.procs.2019.04.089

Bruneo, D., \& De Vita, F. (2019). On the Use of LSTM Networks for Predictive Maintenance in Smart Industries. In 2019 IEEE International Conference on Smart Computing (SMARTCOMP) (p. 241-248).

Bureau, U. C. (2017, October). New york city housing and vacancy survey (nychvs). Retrieved 2018-10-31, from https : //www . census . gov/programs -surveys/nychvs/technical-documentation/code-lists/industry.html

Calabrese, M., Cimmino, M., Fiume, F., Manfrin, M., Romeo, L., Ceccacci, S., ... Kapetis, D. (2020). Sophia: An event-based iot and machine learning architecture for predictive maintenance in industry 4.0. Information, 11, 202.

Candanedo, I., González, S., De la Prieta, F., \& Arrieta, A. (2019). Maspi: A multi agent system for prediction in industry 4.0 environment. Advances in Intelligent Systems and Computing, 771, 197-206. doi: 10.1007/978-3-319-94120-2_19

Canizo, M., Onieva, E., Conde, A., Charramendieta, S., \& Trujillo, S. (2017, June). Real-time predictive maintenance for wind turbines using big data frameworks. In 2017 ieee international conference on prognostics and health management (icphm) (p. 70-77). doi: 10.1109/ICPHM.2017.7998308

Cao, G., Duan, Y., \& Li, G. (2015, August). Linking business analytics to decision making effectiveness: A path model analysis. IEEE Transactions on Engineering Management, 62(3), 384-395. doi: 10.1109/TEM.2015.2441875

Cao, Q., Zanni-Merk, C., Samet, A., De Bertrand de Beuvron, F., \& Reich, C. (2020, January). Using rule quality measures for rule base refinement in knowledge-based predictive maintenance systems. Cybernetics and Systems, 1-16. doi: 10.1080/01969722.2019.1705550

Charest, M., Finn, R., \& Dubay, R. (2018, April). Integration of artificial intelligence in an injection molding process for on-line process parameter adjustment. In 2018 annual ieee international systems conference (syscon) (p. 1-6). doi: 10.1109/SYSCON.2018.8369500

Chen, H., Ling Li, \& Chen, Y. (2020). Explore success factors that impact artificial intelligence adoption on telecom industry in China. Journal of Management Analytics, 8(1), 36-68. doi: 10.1080/23270012.2020.1852895

Chen, Y., Hong Chen, Gorkhali, A., Lu, Y., Ma, Y., \& Li, L. (2016). Big data analytics and big data science: a survey. Journal of Management Analytics, 3(1), 1-42. doi: 10.1080/23270012.2016.1141332

Chen, Y.-J., \& Chien, C.-F. (2018). An empirical study of demand forecasting of non-volatile memory for smart production of semiconductor manufacturing. International Journal of Production Research, 56(13), 4629-4643. doi: 10.1080/00207543.2017.1421783

Chiang, L., Lu, B., \& Castillo, I. (2017). Big data analytics in chemical engineering. Annual Review of Chemical and Biomolecular Engineering, $8,63-85$. doi: 10.1146/annurev-chembioeng-060816-101555

Chi-Hsien, K., \& Nagasawa, S. (2019). Applying machine learning to market analysis: Knowing your luxury consumer. Journal of Management Analytics, 6(4), 404-419. doi: 10.1080/23270012.2019.1692254

Choi, W., Kim, J., Kim, S., \& Kim, J. (2017, October). A study of reference metadata classification with deep learning. In International Conference on 
Information and Communication Technology Convergence (ICTC) (p. 144-146). doi: 10.1109/ICTC.2017.8190961

Chong, D., \& Hui Shi. (2015). Big data analytics: a literature review. Journal of Management Analytics, 2(3), $175-201 . \quad$ doi: 10.1080/23270012.2015.1082449

Cicconi, P., Russo, A. C., Germani, M., Prist, M., Pallotta, E., \& Monteriù, A. (2017, September). Cyber-physical system integration for industry 4.0: Modelling and simulation of an induction heating process for aluminium-steel molds in footwear soles manufacturing. In IEEE $3 \mathrm{rd}$ International Forum on Research and Technologies for Society and Industry (RTSI) (p. 1-6). doi: 10.1109/RTSI.2017.8065972

Cisotto, S., \& Herzallah, R. (2018, December). Performance prediction using neural network and confidence intervals: a gas turbine application. In 2018 ieee international conference on big data (big data) (p. 2151-2159). doi: 10.1109/BigData.2018.8621919

Clegg, D. (2015). Evolving data warehouse and bi architectures: The big data challenge. Business Intelligence Journal, 20(1), $19-24$.

Commission, E. (2020). Digital Europe Programme: A proposed $€ 7.5$ billion of funding for 2021-2027. Retrieved 2021-01-18, from https://ec .europa.eu/digital-single-market/en/news/digital-europe-programme-proposed-eu75-billion-funding-2021-2027

Costa, C., \& Santos, M. Y. (2017). The data scientist profile and its representativeness in the european e-competence framework and the skills framework for the information age. International Journal of Information Management, $37(6), 726$ - $734 . \quad$ doi: https://doi.org/10.1016/j.ijinfomgt.2017.07.010

Costa, R., Figueiras, P., Jardim-Gonçalves, R., Ramos-Filho, J., \& Lima, C. (2017, June). Semantic enrichment of product data supported by machine learning techniques. In 2017 international conference on engineering, technology and innovation (ice/itmc) (p. 1472-1479). doi: 10.1109/ICE.2017.8280056

Davenport, T. H. (2013). Analytics 3.0. Harvard business review, 91(12), 64-72.

de Sá, A., Casimiro, A., Machado, R., \& Carmo, L. (2020). Identification of data injection attacks in networked control systems using noise impulse integration. Sensors (Switzerland), 20(3). doi: 10.3390/s20030792

Diez-Olivan, A., Del Ser, J., Galar, D., \& Sierra, B. (2018, October). Data fusion and machine learning for industrial prognosis: Trends and perspectives towards industry 4.0. Information Fusion, 50, 92-111. doi: 10.1016/j.inffus.2018.10.005

Duan, L., \& Ye Xiong. (2015). Big data analytics and business analytics. Journal of Management Analytics, 2(1), 1-21. doi: $10.1080 / 23270012.2015 .1020891$

Durakbasa, N., Bauer, J., \& Poszvek, G. (2017). Advanced metrology and intelligent quality automation for industry 4.0-based precision manufacturing systems. Solid State Phenomena, 261 SSP, 432-439. doi: 10.4028/www.scientific.net/SSP.261.432

Dutta, R., Mueller, H., \& Liang, D. (2018, April). An interactive architecture for industrial scale prediction: Industry 4.0 adaptation of machine learning. In Annual IEEE International Systems Conference (SysCon) (p. 1-5). doi: 10.1109/SYSCON.2018.8369547

Dwaraka, R., \& Arunachalam, N. (2018). Investigation on non-invasive process monitoring of die sinking edm using acoustic emission signals. Procedia Manufacturing, 26, 1471 - 1482. 46th SME North American Manufacturing Research Conference, NAMRC 46, Texas, USA. doi: 10.1016/j.promfg.2018.07.094

ESRTC. (2009). Technology readiness levels: Handbook for space applications. European Space Research and Technology Centre (ESRTC). Retrieved from https://books.google.pt/books?id=zzYKngEACAAJ

Essien, A., \& Giannetti, C. (2020, January). A deep learning model for smart manufacturing using convolutional Istm neural network autoencoders. IEEE Transactions on Industrial Informatics, PP, 1-1. doi: 10.1109/TII.2020.2967556

European Commission. (2013). Multi-annual roadmap for the contractual PPP under Horizon 2020.

Fu, Y., Ding, J., Wang, H., \& Wang, J. (2018). Two-objective stochastic flow-shop scheduling with deteriorating and learning effect in industry 4.0-based manufacturing system. Applied Soft Computing, 68, 847 - 855. doi: 10.1016/j.asoc.2017.12.009

Geissbauer, R., Vedso, J., \& Schrauf, S. (2016). Industry 4.0: Building the digital enterprise. Retrieved from PwC Website: https://www. pwc. com/gx/en/industries/industries-4.0/landing-page/industry-4.0-building-your-digital-enterprise-april-2016. pdf.

Gomes, M., Silva, F., Ferraz, F., Silva, A., Analide, C., \& Novais, P. (2017). Developing an ambient intelligent-based decision support system for production and control planning. Advances in Intelligent Systems and Computing, 557, 984-994. doi: 10.1007/978-3-319-53480-0_97

Goodfellow, I., Bengio, Y., Courville, A., \& Bengio, Y. (2016). Deep learning. MIT press Cambridge.

Guo, Z., Ngai, E., Yang, C., \& Liang, X. (2015). An RFID-based intelligent decision support system architecture for production monitoring and scheduling in a distributed manufacturing environment. International Journal of Production Economics, 159, 16 - 28. doi: j.ijpe.2014.09.004

Haffner, O., Kucera, E., Š. Kozák, \& Stark, E. (2017, June). Proposal of system for automatic weld evaluation. In 21st International Conference on Process Control (PC) (p. 440-445). doi: 10.1109/PC.2017.7976254

He, M., \& He, D. (2017, May). Deep learning based approach for bearing fault diagnosis. IEEE Transactions on Industry Applications, 53(3), $3057-3065$. doi: $10.1109 /$ TIA.2017.2661250

Hesser, D. F., \& Markert, B. (2019). Tool wear monitoring of a retrofitted cnc milling machine using artificial neural networks. Manufacturing Letters, 19, 1 - 4. doi: 10.1016/j.mfglet.2018.11.001 
Jugulum, R. (2016). Importance of data quality for analytics. In P. Sampaio \& P. Saraiva (Eds.), Quality in the 21st Century: Perspectives from ASQ Feigenbaum Medal Winners (pp. 23-31). Cham: Springer International Publishing. doi: 10.1007/978-3-319-21332-3_2

Kabugo, J. C., Jämsä-Jounela, S.-L., Schiemann, R., \& Binder, C. (2020). Industry 4.0 based process data analytics platform: A waste-to-energy plant case study. International Journal of Electrical Power \& Energy Systems, 115, 105508. doi: 10.1016/j.ijepes.2019.105508

Kagermann, H., Helbig, J., Hellinger, A., \& Wahlster, W. (2013). Recommendations for implementing the strategic initiative industrie 4.0: Securing the future of german manufacturing industry; final report of the industrie 4.0 working group. Forschungsunion.

Karakose, M., \& Yaman, O. (2020). Complex fuzzy system based predictive maintenance approach in railways. IEEE Transactions on Industrial Informatics, 16(9), 6023-6032.

Kaupp, L., Beez, U., Hülsmann, J., \& Humm, B. G. (2019). Outlier detection in temporal spatial log data using autoencoder for industry 4.0. In J. Macintyre, L. Iliadis, I. Maglogiannis, \& C. Jayne (Eds.), Engineering applications of neural networks (pp. 55-65). Cham: Springer International Publishing. doi: 10.1007/978-3-030-20257-6_5

Kharwar, P., Verma, R., Mandal, N., \& Mondal, A. (2020). Swarm intelligence integrated approach for experimental investigation in milling of multiwall carbon nanotube/polymer nanocomposites. Archive of Mechanical Engineering, 67(3), 353-376. doi: 10.24425/ame.2020.131698

Khatri, V., \& Samuel, B. M. (2019, March). Analytics for managerial work. Commun. ACM, 62(4), 100. doi: 10.1145/3274277

Khayyam, H., Jazar, R., Nunna, S., Golkarnarenji, G., Badii, K., Fakhrhoseini, S., .. Naebe, M. (2019, June). Pan precursor fabrication, applications and thermal stabilization process in carbon fiber production: Experimental and mathematical modelling. Progress in Materials Science, 107, 100575. doi: 10.1016/j.pmatsci.2019.100575

Kiangala, K., \& Wang, Z. (2018). Initiating predictive maintenance for a conveyor motor in a bottling plant using industry 4.0 concepts. International Journal of Advanced Manufacturing Technology, 97(9-12), 3251-3271. doi: 10.1007/s00170-018-2093-8

Kim, S., Lee, Y., Adhi Tama, B., \& Lee, S. (2020, May). Reliability-enhanced camera lens module classification using semi-supervised regression method. Applied Sciences, 10, 3832. doi: 10.3390/app10113832

Kirchen, I., Schütz, D., Folmer, J., \& Vogel-Heuser, B. (2017, July). Metrics for the evaluation of data quality of signal data in industrial processes. In 2017 ieee 15th international conference on industrial informatics (indin) (p. 819-826). doi: 10.1109/INDIN.2017.8104878

Kitchenham, B., Brereton, O. P., Budgen, D., Turner, M., Bailey, J., \& Linkman, S. (2009). Systematic literature reviews in software engineering-a systematic literature review. Information and software technology, 51(1), 7-15.

Klement, N., \& Silva, C. (2017). A Generic Decision Support Tool to Planning and Assignment Problems: Industrial Applications and Industry 4.0. In B. Sokolov, D. Ivanov, \& A. Dolgui (Eds.), Scheduling in industry 4.0 and cloud manufacturing (pp. 167-192). Cham: Springer International Publishing. doi: 10.1007/978-3-030-43177-8_9

Koch, R. (2015, Januay). From business intelligence to predictive analytics. Strategic Finance, 96, 56-57.

Kohlert, M., \& König, A. (2016). Advanced multi-sensory process data analysis and on-line evaluation by innovative human-machine-based process monitoring and control for yield optimization in polymer film industry. Technisches Messen, 83(9), 474-483. doi: 10.1515/teme-2015-0120

Krishnamoorthi, S., \& Mathew, S. K. (2018). Business analytics and business value: A comparative case study. Information \& Management, 55(5), 643 - 666. doi: 10.1016/j.im.2018.01.005

Krishnan, K. (2013). Data warehousing in the age of big data (1st ed.). San Francisco, CA, USA: Morgan Kaufmann Publishers Inc.

Kumar, A., Chinnam, R. B., \& Tseng, F. (2018). An HMM and polynomial regression based approach for remaining useful life and health state estimation of cutting tools. Computers \& Industrial Engineering. doi: 10.1016/j.cie.2018.05.017

Kuo, C.-J., Ting, K.-C., Chen, Y.-C., Yang, D.-L., \& Chen, H.-M. (2017). Automatic machine status prediction in the era of industry 4.0: Case study of machines in a spring factory. Journal of Systems Architecture, 81, 44 - 53. doi: 10.1016/j.sysarc.2017.10.007

Kuo, H., \& Faricha, A. (2016). Artificial neural network for diffraction based overlay measurement. IEEE Access, 4, 7479-7486. doi: 10.1109/ACCESS.2016.2618350

Lasi, H., Fettke, P., Kemper, H.-G., Feld, T., \& Hoffmann, M. (2014, August). Industry 4.0. Business \& Information Systems Engineering, 6, $239-242$. doi: 10.1007/s12599-014-0334-4

Lasinkas, J. (2017). Industry 4.0: Penetrating digital technologies reshape global manufacturing sector. Retrieved 2018-06-25, from https://blog . euromonitor.com/2017/01/industry-4-0-penetrating-digital-technologies-reshape-global-manufacturing-sector.html

Lee, J., Kao, H.-A., \& Yang, S. (2014). Service innovation and smart analytics for industry 4.0 and big data environment. Procedia CIRP, 16, 3

- 8. Product Services Systems and Value Creation. Proceedings of the 6th CIRP Conference on Industrial Product-Service Systems. doi: 10.1016/j.procir.2014.02.001

Lee, J., Lapira, E., Bagheri, B., \& Kao, H. (2013). Recent advances and trends in predictive manufacturing systems in big data environment. Manufacturing Letters, 1(1), 38 - 41. doi: 10.1016/j.mfglet.2013.09.005

Lee, W. J., Wu, H., Yun, H., Kim, H., Jun, M., \& Sutheralnd, J. (2019, January). Predictive maintenance of machine tool systems using artificial intelligence techniques applied to machine condition data. Procedia CIRP, 80, 506-511. doi: 10.1016/j.procir.2018.12.019 
Lee, Y.-M., Lin, W. T., Li, M.-H., Xiangqian, Z., \& Li, J.-Y. (2016, November). Research into real-time analysis and exploration of influences on load rate of main shaft of machine of case companies with industry 4.0 technology. In 2016 international conference on fuzzy theory and its applications (ifuzzy) (p. 1-7). doi: 10.1109/iFUZZY.2016.8004968

Leite, M., Pinto, T., \& Alves, C. (2019). A real-time optimization algorithm for the integrated planning and scheduling problem towards the context of industry 4.0. FME Transactions, 47(4), 775-781. doi: 10.5937/fmet1904775L

Lenz, J., Wuest, T., \& Westkämper, E. (2018). Holistic approach to machine tool data analytics. Journal of Manufacturing Systems, 48,180 - 191. Special Issue on Smart Manufacturing. doi: 10.1016/j.jmsy.2018.03.003

$\mathrm{Li}, \mathrm{H}$. (2016, October). An approach to improve flexible manufacturing systems with machine learning algorithms. In lecon 2016 - $42 \mathrm{nd}$ annual conference of the ieee industrial electronics society (p. 54-59). doi: 10.1109/IECON.2016.7793838

Li, S. C., Huang, Y., Tai, B. C., \& Lin, C. T. (2017, November). Using data mining methods to detect simulated intrusions on a modbus network. In IEEE 7th International Symposium on Cloud and Service Computing (SC2) (p. 143-148). doi: 10.1109/SC2.2017.29

Li, Y., Carabelli, S., Fadda, E., Manerba, D., Tadei, R., \& Terzo, O. (2020). Machine learning and optimization for production rescheduling in Industry 4.0. International Journal of Advanced Manufacturing Technology, 110(9-10), 2445-2463. doi: 10.1007/s00170-020-05850-5

Li, Z., Wang, Y., \& Wang, K.-S. (2017). Intelligent predictive maintenance for fault diagnosis and prognosis in machine centers: Industry 4.0 scenario. Advances in Manufacturing, 5(4), 377-387. doi: 10.1007/s40436-017-0203-8

Liang, Y., Kuo, C., \& Lin, C. (2019). A Hybrid Memetic Algorithm for Simultaneously Selecting Features and Instances in Big Industrial loT Data for Predictive Maintenance. In IEEE 17th International Conference on Industrial Informatics (INDIN) (Vol. 1, p. 1266-1270). doi: 10.1109/INDIN41052.2019.8972199

Lin, C., \& Yang, J. (2018). Cost-Efficient Deployment of Fog Computing Systems at Logistics Centers in Industry 4.0. IEEE Transactions on Industrial Informatics, 14(10), 4603-4611. doi: 10.1109/TII.2018.2827920

Lin, C., Shu, L., Deng, D., Yeh, T., Chen, Y., \& Hsieh, H. (2018). A mapreduce-based ensemble learning method with multiple classifier types and diversity for condition-based maintenance with concept drifts. IEEE Cloud Computing, 1-1. doi: 10.1109/MCC.2017.455160123

Lin, T., Chen, Y., Yang, D., \& Chen, Y. (2016, December). New method for industry 4.0 machine status prediction - a case study with the machine of a spring factory. In International Computer Symposium (ICS) (p. 322-326). doi: 10.1109/ICS.2016.0071

Liulys, K. (2019, April). Machine learning application in predictive maintenance. In Open Conference of Electrical, Electronic and Information Sciences (eStream) (p. 1-4). doi: 10.1109/eStream.2019.8732146

Lu, Y. (2019). Artificial intelligence: a survey on evolution, models, applications and future trends. Journal of Management Analytics, 6(1), 1-29. doi: 10.1080/23270012.2019.1570365

Ma, C., \& Li, G. (2018, February). Prediction and Analysis of Tertiary Industry in Financial Center of Xinjiang under "The Belt and Road Initiative". In 10th International Conference on Measuring Technology and Mechatronics Automation (ICMTMA) (p. 143-146). doi: 10.1109/ICMTMA.2018.00041

Maggipinto, M., Terzi, M., Masiero, C., Beghi, A., \& Susto, G. A. (2018, August). A computer vision-inspired deep learning architecture for virtual metrology modeling with 2-dimensional data. IEEE Transactions on Semiconductor Manufacturing, 31(3), 376-384. doi: 10.1109/TSM.2018.2849206

Manyika, J., Chui, M., Brown, B., Bughin, J., Dobbs, R., Roxburgh, C., \& Hung Byers, A. (2011). Big data: The next frontier for innovation, competition, and productivity (Tech. Rep.). McKinsey \& Company. Retrieved from https://www.mckinsey.com/business-functions/digital-mckinsey/ our-insights/big-data-the-next-frontier-for-innovation

Martinek, P., \& Krammer, O. (2019). Analysing machine learning techniques for predicting the hole-filling in pin-in-paste technology. Computers and Industrial Engineering, 136, 187-194. doi: 10.1016/j.cie.2019.07.033

Masoudinejad, M., Venkatapathy, A. K. R., Tondorf, D., Heinrich, D., Falkenberg, R., \& Buschhoff, M. (2018, June). Machine learning based indoor localisation using environmental data in phynetlab warehouse. In Smart SysTech 2018, European Conference on Smart Objects, Systems and Technologies (p. 1-8).

Massaro, A., Manfredonia, I., Galiano, A., Pellicani, L., \& Birardi, V. (2019). Sensing and quality monitoring facilities designed for pasta industry including traceability, image vision and predictive maintenance. In (p. 68-72). Institute of Electrical and Electronics Engineers Inc. doi: 10.1109/METROI4.2019.8792912

Massaro, A., Manfredonia, I., Galiano, A., \& Xhahysa, B. (2019). Advanced process defect monitoring model and prediction improvement by artificial neural network in kitchen manufacturing industry: A case of study. In IEEE International Workshop on Metrology for Industry 4.0 and IoT, Metrolnd 4.0 and IoT 2019 - Proceedings (p. 64-67). Institute of Electrical and Electronics Engineers Inc. doi: 10.1109/METROI4.2019.8792872

Mell, P. M., \& Grance, T. (2011). SP 800-145. The NIST Definition of Cloud Computing (Tech. Rep.). Gaithersburg, MD, United States: National Institute of Standards \& Technology.

Milošević, M., Durdev, M., Lukić, D., Antić, A., \& Ungureanu, N. (2020). Intelligent process planning for smart factory and smart manufacturing. 
Lecture Notes in Mechanical Engineering, 205-214. doi: 10.1007/978-3-030-46212-3_14

Miškuf, M., \& Zolotová, I. (2016, February). Comparison between multi-class classifiers and deep learning with focus on industry 4.0. In Cybernetics Informatics (KI) (p. 1-5). doi: 10.1109/CYBERI.2016.7438633

Mohanty, S., Jagadeesh, M., \& Srivatsa, H. (2013). Big data imperatives: Enterprise big data warehouse, bi implementations and analytics (1st ed.). Berkely, CA, USA: Apress.

Mozgova, I., Yanchevskyi, I., Gerasymenko, M., \& Lachmayer, R. (2018). Mobile automated diagnostics of stress state and residual life prediction for a component under intensive random dynamic loads. Procedia Manufacturing, 24, 210 - 215. 4th International Conference on SystemIntegrated Intelligence: Intelligent, Flexible and Connected Systems in Products and Production. doi: 10.1016/j.promfg.2018.06.037

Muhuri, P., Shukla, A., \& Abraham, A. (2019, February). Industry 4.0: A bibliometric analysis and detailed overview. Engineering Applications of Artificial Intelligence, 78, 218-235. doi: 10.1016/j.engappai.2018.11.007

Mulrennan, K., Donovan, J., Creedon, L., Rogers, I., Lyons, J. G., \& McAfee, M. (2018). A soft sensor for prediction of mechanical properties of extruded pla sheet using an instrumented slit die and machine learning algorithms. Polymer Testing, 69, 462 - $469 . \quad$ doi: 10.1016/j.polymertesting.2018.06.002

Naskos, A., Gounaris, A., Metaxa, I., \& Köchling, D. (2019). Detecting anomalous behavior towards predictive maintenance. In H. A. Proper \& J. Stirna (Eds.), Advanced information systems engineering workshops (pp. 73-82). Cham: Springer International Publishing. doi: 10.1007/9783-030-20948-3_7

Negri, E., Ardakani, H., Cattaneo, L., Singh, J., MacChi, M., \& Lee, J. (2019). A Digital Twin-based scheduling framework including Equipment Health Index and Genetic Algorithms. IFAC-PapersOnLine, 52(10), 43-48. doi: 10.1016/j.ifacol.2019.10.024

Neuböck, T., \& Schrefl, M. (2015). Modelling knowledge about data analysis processes in manufacturing. IFAC-PapersOnLine, $48(3), 277$ - 282. doi: 10.1016/j.ifacol.2015.06.094

Nikolic, B., Ignjatic, J., Suzic, N., Stevanov, B., \& Rikalovic, A. (2017). Predictive manufacturing systems in industry 4.0: Trends, benefits and challenges. In 28th daaam international symposium on intelligent manufacturing and automation (p. 796-802). doi: 10.2507/28th.daaam.proceedings.112

Niño, M., Blanco, J. M., \& Illarramendi, A. (2015, October). Business understanding, challenges and issues of big data analytics for the servitization of a capital equipment manufacturer. In IEEE International Conference on Big Data (Big Data) (p. 1368-1377). doi: 10.1109/BigData.2015.7363897

Nuzzi, C., Pasinetti, S., Lancini, M., Docchio, F., \& Sansoni, G. (2018, April). Deep Learning Based Machine Vision: First Steps Towards a Hand Gesture Recognition Set Up for Collaborative Robots. In Workshop on Metrology for Industry 4.0 and loT (p. 28-33). doi: 10.1109/METROI4.2018.8439044

Öchsner, A. (2013). Types of scientific publications. In Introduction to scientific publishing: Backgrounds, concepts, strategies (p. 9-21). Berlin, Heidelberg: Springer Berlin Heidelberg. doi: 10.1007/978-3-642-38646-6_3

O'Donovan, P., Leahy, K., Bruton, K., \& O'Sullivan, D. T. J. (2015, September). Big data in manufacturing: a systematic mapping study. Journal of Big Data, 2(1), 20. doi: 10.1186/s40537-015-0028-x

Packianather, M. S., Munizaga, N. L., Zouwail, S., \& Saunders, M. (2019, May). Development of soft computing tools and iot for improving the performance assessment of analysers in a clinical laboratory. In 14th Annual Conference System of Systems Engineering (SoSE) (p. 158-163). doi: 10.1109/SYSOSE.2019.8753830

Pane, Y., Nageshrao, S., Kober, J., \& Babuska, R. (2019, February). Reinforcement learning based compensation methods for robot manipulators. Engineering Applications of Artificial Intelligence, 78, 236-247. doi: 10.1016/j.engappai.2018.11.006

Park, C. Y., Laskey, K. B., Salim, S., \& Lee, J. Y. (2017, July). Predictive situation awareness model for smart manufacturing. In 20th International Conference on Information Fusion (Fusion) (p. 1-8). doi: 10.23919/ICIF.2017.8009849

Peralta, G., Iglesias-Urkia, M., Barcelo, M., Gomez, R., Moran, A., \& Bilbao, J. (2017, May). Fog computing based efficient loT scheme for the Industry 4.0. In IEEE International Workshop of Electronics, Control, Measurement, Signals and their Application to Mechatronics (ECMSM) (p. 1-6). doi: 10.1109/ECMSM.2017.7945879

Pierezan, J., Maidl, G., Massashi Yamao, E., dos Santos Coelho, L., \& Cocco Mariani, V. (2019). Cultural coyote optimization algorithm applied to a heavy duty gas turbine operation. Energy Conversion and Management, 199. doi: 10.1016/j.enconman.2019.111932

Pinto, R., \& Cerquitelli, T. (2019). Robot fault detection and remaining life estimation for predictive maintenance. Procedia Computer Science, 151, 709-716. doi: 10.1016/j.procs.2019.04.094

Plehiers, P., Symoens, S., Amghizar, I., Marin, G., Stevens, C., \& Van Geem, K. (2019). Artificial intelligence in steam cracking modeling: A deep learning algorithm for detailed effluent prediction. Engineering. doi: 10.1016/j.eng.2019.02.013

Ploennigs, J., Ba, A., \& Barry, M. (2018, August). Materializing the promises of cognitive iot: How cognitive buildings are shaping the way. IEEE Internet of Things Journal, 5(4), 2367-2374. doi: 10.1109/JIOT.2017.2755376 
Pradhan, K., \& Chawla, P. (2020). Medical Internet of things using machine learning algorithms for lung cancer detection. Journal of Management Analytics, 7(4), 591-623. doi: 10.1080/23270012.2020.1811789

Proto, S., Ventura, F., Apiletti, D., Cerquitelli, T., Baralis, E., Macii, E., \& Macii, A. (2019). Premises, a scalable data-driven service to predict alarms in slowly-degrading multi-cycle industrial processes. In IEEE International Congress on Big Data, BigData Congress 2019 - Part of the 2019 IEEE World Congress on Services (p. 139-143). Institute of Electrical and Electronics Engineers Inc. doi: 10.1109/BigDataCongress.2019.00032

Qi, Q., \& Tao, F. (2018). Digital twin and big data towards smart manufacturing and industry 4.0: 360 degree comparison. IEEE Access, 6, $3585-3593$. doi: 10.1109/ACCESS.2018.2793265

Qin, J., Liu, Y., \& Grosvenor, R. (2016). A categorical framework of manufacturing for industry 4.0 and beyond. Procedia Cirp, 52, $173-178$.

Qin, J., Liu, Y., \& Grosvenor, R. (2017, August). Data analytics for energy consumption of digital manufacturing systems using internet of things method. In 13th IEEE Conference on Automation Science and Engineering (CASE) (p. 482-487). doi: 10.1109/COASE.2017.8256150

Qu, S., Wang, J., Govil, S., \& Leckie, J. O. (2016). Optimized adaptive scheduling of a manufacturing process system with multi-skill workforce and multiple machine types: An ontology-based, multi-agent reinforcement learning approach. Procedia CIRP, 57, 55 - 60. Factories of the Future in the digital environment - Proceedings of the 49th CIRP Conference on Manufacturing Systems. doi: 10.1016/j.procir.2016.11.011

Rahman, H., Janardhanan, M., \& Nielsen, P. (2020). An integrated approach for line balancing and AGV scheduling towards smart assembly systems. Assembly Automation, 40(2), 219-234. doi: 10.1108/AA-03-2019-0057

Rendall, R., Castillo, I., Lu, B., Colegrove, B., Broadway, M., Chiang, L. H., \& Reis, M. S. (2018). Image-based manufacturing analytics: Improving the accuracy of an industrial pellet classification system using deep neural networks. Chemometrics and Intelligent Laboratory Systems, 180,26 35. doi: 10.1016/j.chemolab.2018.07.001

Rich, S. (2012). Big Data Is a 'New Natural Resource' IBM Says. Retrieved 2018-01-07, from http://www.govtech.com/policy-management/ Big-Data-Is-a-New-Natural-Resource-IBM-Says.html

Richter, J., Streitferdt, D., \& Rozova, E. (2017, January). On the development of intelligent optical inspections. In IEEE 7th Annual Computing and Communication Workshop and Conference (CCWC) (p. 1-6). doi: 10.1109/CCWC.2017.7868455

Rogier, J., \& Mohamudally, N. (2019). Forecasting photovoltaic power generation via an loT network using nonlinear autoregressive neural network. Procedia Computer Science, 151, 643-650. doi: 10.1016/j.procs.2019.04.086

Romeo, L., Paolanti, M., Bocchini, G., Loncarski, J., \& Frontoni, E. (2018, September). An Innovative Design Support System for Industry 4.0 Based on Machine Learning Approaches. In 5th International Symposium on Environment-Friendly Energies and Applications (EFEA) (p. 1-6). doi: 10.1109/EFEA.2018.8617089

Rosli, N., Ain Burhani, N., \& Ibrahim, R. (2019). Predictive Maintenance of Air Booster Compressor (ABC) Motor Failure using Artificial Neural Network trained by Particle Swarm Optimization. In IEEE Student Conference on Research and Development (SCOReD) (p. 11-16). Institute of Electrical and Electronics Engineers Inc. doi: 10.1109/SCORED.2019.8896330

Rousopoulou, V., Nizamis, A., Giugliano, L., Haigh, P., Martins, L., loannidis, D., \& Tzovaras, D. (2019). Data analytics towards predictive maintenance for industrial ovens. In H. A. Proper \& J. Stirna (Eds.), Advanced information systems engineering workshops (pp. 83-94). Cham: Springer International Publishing. doi: 10.1007/978-3-030-20948-3_8

Ruiz-Sarmiento, J., Monroy, J., Moreno, F.-A., Galindo, C., Bonelo, J., \& González-Jiménez, J. (2020, January). A predictive model for the maintenance of industrial machinery in the context of industry 4.0. Engineering Applications of Artificial Intelligence, 87, 103289. doi: 10.1016/j.engappai.2019.103289

Russom, P. (2014). Evolving data warehouse architectures in the age of big data. The Data Warehousing Institute (TDWI).

Russom, P. (2016). Data warehouse modernization in the age of big data analytics. The Data Warehousing Institute (TDWI).

Saldivar, A. A. F., Goh, C., Chen, W., \& Li, Y. (2016, July). Self-organizing tool for smart design with predictive customer needs and wants to realize industry 4.0. In 2016 ieee congress on evolutionary computation (cec) (p. 5317-5324). doi: 10.1109/CEC.2016.7748366

Saldivar, A. A. F., Goh, C., Li, Y., Chen, Y., \& Yu, H. (2016, September). Identifying smart design attributes for industry 4.0 customization using a clustering genetic algorithm. In 22nd International Conference on Automation and Computing (ICAC) (p. 408-414). doi: 10.1109/IConAC.2016.7604954

Saldivar, A. A. F., Goh, C., Li, Y., Yu, H., \& Chen, Y. (2016, December). Attribute identification and predictive customisation using fuzzy clustering and genetic search for industry 4.0 environments. In 10th International Conference on Software, Knowledge, Information Management Applications (SKIMA) (p. 79-86). doi: 10.1109/SKIMA.2016.7916201

Sanz, E., Matey, J. L., Blesa, J., \& Puig, V. (2017, April). Advanced monitoring of an industrial process integrating several sources of information through a data warehouse. In 4th International Conference on Control, Decision and Information Technologies (CoDIT) (p. 0521-0526). doi: 10.1109/CoDIT.2017.8102646

Saxena, V. K., \& Pushkar, S. (2016, March). Cloud computing challenges and implementations. In International Conference on Electrical, Electronics, and Optimization Techniques (ICEEOT) (p. 2583-2588). doi: 10.1109/ICEEOT.2016.7755159 
Sellami, C., Miranda, C., Samet, A., Bach Tobji, M., \& de Beuvron, F. (2019). On mining frequent chronicles for machine failure prediction. Journal of Intelligent Manufacturing. doi: 10.1007/s10845-019-01492-x

Senkerik, R., Kadavy, T., Viktorin, A., \& Pluhacek, M. (2019). Ensemble of Strategies and Perturbation Parameter Based SOMA for Constrained Technological Design Optimization Problem. In IEEE Congress on Evolutionary Computation, CEC 2019 - Proceedings (p. 2872-2877). doi: 10.1109/CEC.2019.8790047

Sezer, E., Romero, D., Guedea, F., Macchi, M., \& Emmanouilidis, C. (2018, June). An Industry 4.0-Enabled Low Cost Predictive Maintenance Approach for SMEs. In IEEE International Conference on Engineering, Technology and Innovation (ICE/ITMC) (p. 1-8). doi: 10.1109/ICE.2018.8436307

Sharp, M., Ak, R., \& Hedberg, T. (2018). A survey of the advancing use and development of machine learning in smart manufacturing. Journal of Manufacturing Systems, 48, 170 - 179. Special Issue on Smart Manufacturing. doi: 10.1016/j.jmsy.2018.02.004

Shrouf, F., Ordieres, J., \& Miragliotta, G. (2014, December). Smart factories in industry 4.0: A review of the concept and of energy management approached in production based on the internet of things paradigm. In IEEE International Conference on Industrial Engineering and Engineering Management (p. 697-701). doi: 10.1109/IEEM.2014.7058728

Silva, D., Jesus, K., Villaverde, B., \& Adina, E. (2020, February). Hybrid Artificial Neural Network and Genetic Algorithm Model for Multi-Objective Strength Optimization of Concrete with Surkhi and Buntal Fiber. In Proceedings of the 12th International Conference on Computer and Automation Engineering (p. 47-51). doi: 10.1145/3384613.3384617

Soto, J. A. C., Tavakolizadeh, F., \& Gyulai, D. (2019). An online machine learning framework for early detection of product failures in an industry 4.0 context. International Journal of Computer Integrated Manufacturing, 32(4-5), 452-465. doi: 10.1080/0951192X.2019.1571238

Spendla, L., Kebisek, M., Tanuska, P., \& Hrcka, L. (2017, January). Concept of predictive maintenance of production systems in accordance with industry 4.0. In IEEE 15th International Symposium on Applied Machine Intelligence and Informatics (SAMI) (p. 000405-000410). doi: 10.1109/SAMI.2017.7880343

Stein, B. V., Leeuwen, M. V., Wang, H., Purr, S., Kreissl, S., Meinhardt, J., \& Bäck, T. (2016, December). Towards Data Driven Process Control in Manufacturing Car Body Parts. In International Conference on Computational Science and Computational Intelligence (CSCI) (p. 459-462). doi: 10.1109/CSCI.2016.0093

Straus, P., Schmitz, M., Wostmann, R., \& Deuse, J. (2018, December). Enabling of Predictive Maintenance in the Brownfield through LowCost Sensors, an IloT-Architecture and Machine Learning. In IEEE International Conference on Big Data (Big Data) (p. 1474-1483). doi: 10.1109/BigData.2018.8622076

Stürmlinger, T., Haar, C., Pandtle, J., \& Niemeyer, V. (2018). Development of a wear model of a manufacturing system based on external smart production data on the example of a spring coiling machine. Procedia CIRP, 72, 232 - 236. 51st CIRP Conference on Manufacturing Systems. doi: 10.1016/j.procir.2018.03.260

Subakti, H., \& Jiang, J. (2018, July). Indoor Augmented Reality Using Deep Learning for Industry 4.0 Smart Factories. In IEEE 42nd Annual Computer Software and Applications Conference (COMPSAC) (Vol. 02, p. 63-68). doi: 10.1109/COMPSAC.2018.10204

Subramaniyan, M., Skoogh, A., Salomonsson, H., Bangalore, P., \& Bokrantz, J. (2018). A data-driven algorithm to predict throughput bottlenecks in a production system based on active periods of the machines. Computers \& Industrial Engineering. doi: 10.1016/j.cie.2018.04.024

Sun, I. ., \& Chen, K. (2017, September). Development of signal transmission and reduction modules for status monitoring and prediction of machine tools. In 56th Annual Conference of the Society of Instrument and Control Engineers of Japan (SICE) (p. 711-716). doi: 10.23919/SICE.2017.8105459

Susto, G. A., Schirru, A., Pampuri, S., Beghi, A., \& DeNicolao, G. (2018). A hidden-gamma model-based filtering and prediction approach for monotonic health factors in manufacturing. Control Engineering Practice, 74, 84 - 94. doi: 10.1016/j.conengprac.2018.02.011

Swamy, A. K., \& B. Sarojamma. (2020). Bank transaction data modeling by optimized hybrid machine learning merged with ARIMA. Journal of Management Analytics, 7(4), 624-648. doi: 10.1080/23270012.2020.1726217

Tan, Y., Goddard, S., \& Pérez, L. C. (2008, January). A prototype architecture for cyber-physical systems. SIGBED Rev., 5(1), 26:1-26:2. doi: $10.1145 / 1366283.1366309$

Tang, D., Zheng, K., Zhang, H., Sang, Z., Zhang, Z., Xu, C., ... Zechinelli-Martini, J.-L. (2016). Using Autonomous Intelligence to Build a Smart Shop Floor. Procedia CIRP, 56, 354 - 359. The 9th International Conference on Digital Enterprise Technology - Intelligent Manufacturing in the Knowledge Economy Era. doi: 10.1016/j.procir.2016.10.039

Teschemacher, U., \& Reinhart, G. (2017). Ant colony optimization algorithms to enable dynamic milkrun logistics. Procedia CIRP, 63,762 - 767. Manufacturing Systems 4.0 - Proceedings of the 50th CIRP Conference on Manufacturing Systems. doi: 10.1016/j.procir.2017.03.125

Tieng, H., Tsai, T., Chen, C., Yang, H., Huang, J., \& Cheng, F. (2018, April). Automatic virtual metrology and deformation fusion scheme for engine-case manufacturing. IEEE Robotics and Automation Letters, 3(2), 934-941. doi: 10.1109/LRA.2018.2792690

Tiwari, K., Shaik, A., \& N, A. (2018). Tool wear prediction in end milling of ti-6al-4v through kalman filter based fusion of texture features and cutting forces. Procedia Manufacturing, 26, 1459 - 1470. 46th SME North American Manufacturing Research Conference, NAMRC 46, Texas, 
USA. doi: 10.1016/j.promfg.2018.07.095

Tjahjono, B., Esplugues, C., Ares, E., \& Pelaez, G. (2017). What does industry 4.0 mean to supply chain? Procedia Manufacturing, 13, 1175 1182. Manufacturing Engineering Society International Conference 2017, MESIC 2017, 28-30 June 2017, Vigo (Pontevedra), Spain. doi: 10.1016/j.promfg.2017.09.191

Trunzer, E., Weiß, I., Folmer, J., Schrüfer, C., Vogel-Heuser, B., Erben, S., ... Vermum, C. (2017, December). Failure mode classification for control valves for supporting data-driven fault detection. In 2017 ieee international conference on industrial engineering and engineering management (ieem) (p. 2346-2350). doi: 10.1109/IEEM.2017.8290311

Tsai, S., \& Chang, J. J. (2018, February). Parametric study and design of deep learning on leveling system for smart manufacturing. In IEEE International Conference on Smart Manufacturing, Industrial Logistics Engineering (SMILE) (p. 48-52). doi: 10.1109/SMILE.2018.8353980

Tsourma, M., Zikos, S., Drosou, A., \& Tzovaras, D. (2018, April). Online task distribution simulation in smart factories. In 2nd International Symposium on Small-scale Intelligent Manufacturing Systems (SIMS) (p. 1-6). doi: 10.1109/SIMS.2018.8355301

Uhlmann, E., Hohwieler, E., \& Geisert, C. (2017). Intelligent production systems in the era of Industrie 4.0-changing mindsets and business models. Journal of Machine Engineering, 17.

Uriarte, A. G., Ng, A. H., \& Moris, M. U. (2018). Supporting the lean journey with simulation and optimization in the context of industry 4.0. Procedia Manufacturing, 25, 586 - 593. Proceedings of the 8th Swedish Production Symposium (SPS 2018). doi: 10.1016/j.promfg.2018.06.097

Vathoopan, M., Johny, M., Zoitl, A., \& Knoll, A. (2018). Modular fault ascription and corrective maintenance using a digital twin. IFACPapersOnLine, 51(11), 1041 - 1046. 16th IFAC Symposium on Information Control Problems in Manufacturing INCOM $2018 . \quad$ doi: 10.1016/j.ifacol.2018.08.470

Vazan, P., Janikova, D., Tanuska, P., Kebisek, M., \& Cervenanska, Z. (2017). Using data mining methods for manufacturing process control. IFACPapersOnLine, 50(1), 6178 - 6183. doi: 10.1016/j.ifacol.2017.08.986

Ventura, F., Proto, S., Apiletti, D., Cerquitelli, T., Panicucci, S., Baralis, E., ... Macii, A. (2019). A New Unsupervised Predictive-Model Self-Assessment Approach That SCALEs. In IEEE International Congress on Big Data (p. 144-148). Institute of Electrical and Electronics Engineers Inc. doi: 10.1109/BigDataCongress.2019.00033

Wan, J., Tang, S., Li, D., Wang, S., Liu, C., Abbas, H., \& Vasilakos, A. V. (2017, August). A manufacturing big data solution for active preventive maintenance. IEEE Transactions on Industrial Informatics, 13(4), 2039-2047. doi: 10.1109/TII.2017.2670505

Wang, Y., Tercan, H., Thiele, T., Meisen, T., Jeschke, S., \& Schulz, W. (2017, November). Advanced data enrichment and data analysis in manufacturing industry by an example of laser drilling process. In ITU Kaleidoscope: Challenges for a Data-Driven Society (ITU K) (p. 1-5). doi: 10.23919/ITUWT.2017.8246990

Wang, Y.-M., Wang, Y.-S., \& Yang, Y.-F. (2010). Understanding the determinants of rfid adoption in the manufacturing industry. Technological Forecasting and Social Change, 77(5), 803 - 815. doi: 10.1016/j.techfore.2010.03.006

Wu, W., Zheng, Y., Chen, K., Wang, X., \& Cao, N. (2018, April). A Visual Analytics Approach for Equipment Condition Monitoring in Smart Factories of Process Industry. In IEEE Pacific Visualization Symposium (PacificVis) (p. 140-149). doi: 10.1109/PacificVis.2018.00026

Xia, F., Yang, L. T., Wang, L., \& Vinel, A. (2012, September). Internet of things. Int. J. Commun. Syst., 25(9), 1101-1102. doi: 10.1002/dac.2417

Xu, L. D., He, W., \& Li, S. (2014, November). Internet of things in industries: A survey. IEEE Transactions on Industrial Informatics, 10(4), $2233-2243$. doi: 10.1109/TII.2014.2300753

Xu, X. (2012). From cloud computing to cloud manufacturing. Robotics and Computer-Integrated Manufacturing, $28(1), 75$ - $86 . \quad$ doi: 10.1016/j.rcim.2011.07.002

Xu, X., \& Hua, Q. (2017). Industrial big data analysis in smart factory: Current status and research strategies. IEEE Access, 5, 17543-17551. doi: 10.1109/ACCESS.2017.2741105

Yan, H., Wan, J., Zhang, C., Tang, S., Hua, Q., \& Wang, Z. (2018). Industrial big data analytics for prediction of remaining useful life based on deep learning. IEEE Access, 6, 17190-17197. doi: 10.1109/ACCESS.2018.2809681

Yan, J., Meng, Y., Lu, L., \& Li, L. (2017). Industrial big data in an industry 4.0 environment: Challenges, schemes, and applications for predictive maintenance. IEEE Access, 5, 23484-23491. doi: 10.1109/ACCESS.2017.2765544

Yang, H., \& Tate, M. (2009, December). Where are we at with Cloud Computing?: A Descriptive Literature Review. In ACIS 2009 Proceedings - 20th Australasian Conference on Information Systems (p. 807-819). Melbourne, Australia.

Yang, J., Chen, Y., Huang, W., \& Li, Y. (2017, September). Survey on artificial intelligence for additive manufacturing. In 23rd International Conference on Automation and Computing (ICAC) (p. 1-6). doi: 10.23919/IConAC.2017.8082053

Yeh, C., W.C. and Lai, \& Tsai, J. (2019). Simplified swarm optimization for optimal deployment of fog computing system of industry 4.0 smart factory. Journal of Physics: Conference Series, 1411(1). doi: 10.1088/1742-6596/1411/1/012005

Zenisek, J., Wolfartsberger, J., Sievi, C., \& Affenzeller, M. (2019). Modeling sensor networks for predictive maintenance. In C. Debruyne, H. Panetto, W. Guédria, P. Bollen, I. Ciuciu, \& R. Meersman (Eds.), On the Move to Meaningful Internet Systems: OTM 2018 Workshops (pp. 184-188). Cham: 
Springer International Publishing. doi: 10.1007/978-3-030-11683-5_20

Zhang, Q., Cheng, L., \& Boutaba, R. (2010, May). Cloud computing: state-of-the-art and research challenges. Journal of Internet Services and Applications, 1(1), 7-18. doi: 10.1007/s13174-010-0007-6

Zhang, T., Feng, Y., \& Hao, B. (2019). Industrial intelligent forecast of tft-Icd based on r-svm. In (p. 25-30). Institute of Electrical and Electronics Engineers Inc. doi: 10.1109/ICIAICT.2019.8784848

Zheng, M., \& Wu, K. (2017). Smart spare parts management systems in semiconductor manufacturing. Industrial Management \& Data Systems, 117(4), 754-763. doi: 10.1108/IMDS-06-2016-0242

Zhong, R. Y., Xu, X., Klotz, E., \& Newman, S. T. (2017). Intelligent manufacturing in the context of industry 4.0: A review. Engineering, 3(5), 616 630. doi: 10.1016/J.ENG.2017.05.015

Zhou, H., \& Yu, K. (2017, August). Imbalanced data classification for defective product prediction based on industrial wireless sensor network. In Sixth International Conference on Future Generation Communication Technologies (FGCT) (p. 1-6). doi: 10.1109/FGCT.2017.8103728

\section{AUTHOR BIOGRAPHY}

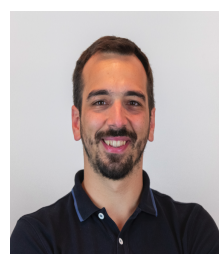

António João Silva is a Ph.D. candidate and a R\&D Engineer at the Digital Transformation CoLab (DTx CoLab), Portugal. He received his M.Sc. in Information Systems Management and Engineering, University of Minho. He is also member of the ALGORITMI R\&D center and his main research interests lie on Machine Learning and Data Science.

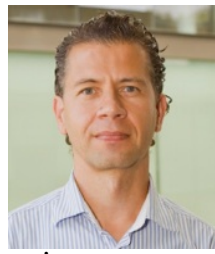

Paulo Cortez (Habilitation, Ph.D.) is Associate Professor at the Department of Information Systems, University of Minho, Portugal. He is also assistant director of the ALGORITMI R\&D center. Currently, he is Associate Editor of the journals Decision Support Systems (Elsevier) and Expert Systems (Wiley). His research, within the fields of Decision Support, Data Science, Machine Learning and Modern Optimization, has appeared in Journal of Heuristics, Decision Support Systems, Information Sciences, Expert Systems and others (see http://www3.dsi.uminho.pt/pcortez.

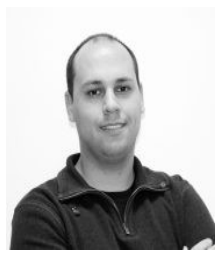

Carlos Pereira is currently a Senior R\&D Specialist at Efacec, Portugal. He received his Ph.D. in Electrical and Computer Engineering from the University of Porto in 2017. He is co-autor of several indexed publications in international journals and conferences. His research interests focus on the application of advanced Artificial Intelligence and Machine Learning techniques to different industry fields.

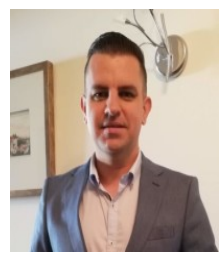

André Pilastri is a Ph.D. candidate in Informatics Engineering at University of Porto, Portugal. He received his M.Sc. in Computer Science from the São Paulo State University (UNESP), Brazil, in 2012. Currently, he is a Senior Machine Learning Engineer at the Center Computer Graphics, Portugal, with research interests in the areas of Applied Machine Learning, Data Science and Industry 4.0. 